Original Research Paper

\title{
Comparing Approaches for Quality Evaluation of Software Engineering Experiments: An Empirical Study on Software Product Line Experiments
}

\author{
Viviane R. Furtado, Henrique Vignando, Victor França and Edson OliveiraJr \\ Informatics Department, State University of Maringá, Maringá-PR, Brazil
}

\author{
Article history \\ Received: 09-11-2018 \\ Revised: 28-03-2019 \\ Accepted: 23-04-2019 \\ Corresponding Author: \\ Edson OliveiraJr \\ Informatics Department, \\ State University of Maringá, \\ Maringá-PR, Brazil \\ Email: edson@din.uem.br
}

\begin{abstract}
The Software Engineering (SE) research area must provide results of a certain quality for the sake of value. High quality research results may ensure experience and knowledge, which are essential for the technology to be transferred to the industry. One of the means to obtain such quality results is experimentation. Experimentation is a scientific method that aims to provide evidence of a theory over real-world observations establishing a cause-effect relation. Well conducted, auditable and repeatable experiments are vital for scientific evolution and novelty. Quality evaluation of controlled experiments and quasi-experiments in SE has been recently discussed in the literature as researchers desire to assess whether such experiments have improved by reporting information that enables the experiments to be replicated and the reader can understand the experiment and validate results. Thus, this work empirically compares four approaches for quality evaluation of SE experiments in the context of Software Product Lines (SPL). In addition, we are interested on verifying the quality of reporting experiments in a well-discussed reuse technique as SPL. The Pearson technique supported the correlation between pairs of evaluation approaches. In addition, the T-Test and Mann-WhitneyWilcoxon $U$ test were applied to the samples to verify whether there was a difference in the quality of experiments when using an experimental template. Preliminary results show a strong positive correlation between them, the hypothesis tests confirmed there is such a difference in quality when using experimental template and the SPL experiments report more the planning phase than the analysis and interpretation phase. Based on our results, we provide initial evidence two approaches are the best to reporting SPL experiments.
\end{abstract}

Keywords: Experiments, Quasi-Experiments, Quality Evaluation of Experiments, Software Product Line

\section{Introduction}

Experimentation in the Software Engineering (SE) area plays a central role at providing evidence of a certain theory in an objective, accurate and systematic way (Wohlin et al., 2012), as well as providing inductive support for hypotheses (Sjoberg et al., 2007) and decision making, aiding the comparison of different technologies, methods and tools (Kampenes, 2007).

Therefore, evaluating the quality of experiments and quasi-experiments (In this work we use the term "experiment" to denote both concepts of "experiment" and "quasi-experiment".) is essential for improving the means to carry out experiments (Kitchenham et al., 2012) towards development and sharing scientific knowledge and empirical decisions on software construction based on software engineering (Sjoberg et al., 2007).

The software engineering community has discussed how to evaluate the quality of experiments using approaches, such as: Simple quality criteria (Dieste et al., 2011), checklists (Kampenes, 2007; Kitchenham and Charters, 2007; Kitchenham et al., 2010), quality scales (Dieste et al., 2011) and inference validity and experiments reporting (Kampenes, 2007). 
One of the points they discuss is the lack of consensus on the definition of quality in the research community. Thus, it has been suggested that quality is related to minimizing the bias and maximizing the internal and external validity of the experiments (Dieste et al., 2011). Such a suggestion was investigated by the Dieste et al. (2011) approach and the preliminary results affirmed the relationship between bias and internal validity. Some approaches have been applied in experiments in the SE domain, software inspection, pair programming and human-centric, selected throughout systematic literature reviews.

Existing literature provides four approaches to evaluate the quality of SE experiments:

- A1 - the Kitchenham and Charters (2007) checklist;

- A2 - the Kampenes (2007) checklist;

- A3 - the Kitchenham et al. (2010) checklist;

- $\quad$ A4 - the Dieste et al. (2011) quality scale.

Thus, it is necessary to know each one of them, as well as they are structured to evaluate the quality of the SE experiments. An emerging growth area is Software Product Line (SPL), which aims to generate specific products based on the reuse of a central infrastructure (Linden et al., 2007). A large number of experiments have been conducted on a wide range of subjects related to SPL. Such experiments are important in providing evidence to the industry and to the academia, seeking the transfer of technology through a reliable and auditable body of knowledge. In this way, being able to evaluate the quality of an experiment becomes essential to achieve such objectives with the researches.

Therefore, this paper describes an empirical study performed to comparing the mentioned approaches in terms of: (i) Quality of experiments, (ii) usage of a template for experimental reporting and (iii) granularity the approach questions.

Results obtained with this empirical study indicate a significant correlation between pairs of quality evaluation approaches of SE experiments applied in the SPL context. Pearson's correlation was applied and was strong positive for all pairs of evaluated approaches. The A2 (Kampenes, 2007) and A3 (Kitchenham et al., 2010) approaches pair presented the highest correlation with 0.883 , which were the ones that achieved the best results in the variables "Usage of templates for experimental reporting" and "Granularity of questions from the approaches". Thus, A2 and A3 approaches are the best for reporting SPL experiments.

This paper is structured as follows: Section 2 presents the essential concepts with regard to the quality evaluation of experiments in SE, SPL, SPL experimentation and related work; section 3 reports the empirical study conducted; and section 4 presents conclusions and directions for future work.

\section{Background and Related Work}

This section presents initial concepts for this work.

\section{Quality Evaluation of Experiments in Software Engineering}

The quality of SE experiments can be observed in regarding to the amount of bias in the experimental results (Dieste and Juristo, 2013). As bias cannot be measured, there are approaches to evaluate it (Dieste et al., 2011; Dieste and Juristo, 2013), such as:

- Simple approaches: A set of validity criteria, usually answered in a qualitative way, applying a classification scale

- Checklists: Based on quality items, in which they are not punctuated numerically, such as a considerable number of quality related questions answered with "Yes/No"

- Quality Scales: Based on a series of quality items, numerically punctuated to provide a quantitative assessment of the overall quality of the study. Punctuation tends to be subjective, as it can be generated by weighing all items in the same way or assigning them different weights in relation to the importance of the evaluated criteria

- Expert opinion: One or several experts provide an evaluation of the quality of an experiment based on its nominal value, i.e., a subjective evaluation of the overall quality of the paper based on an ordinal scale of 5 points (excellent (5), very good (4), acceptable (3), poor (2) and unacceptable (1)), being able to distinguish experiments with high and low quality

The experimental quality in SE can also be evaluated considering the design and analysis of the experiments, in terms of statistical power, effect size analysis, quasi-experimentation and experiment report (Kampenes, 2007).

The following are approaches to quality evaluation of SE experiments found in the literature.

\section{The Kitchenham and Charters Approach}

The quality evaluation checklist for SE experiments proposed by Kitchenham and Charters (2007) contains 52 questions divided into design, conduct, analysis and conclusions, suggesting researchers to select only the most appropriate checklist questions to the context of their own research questions (see Table 6, Table 7 and Table 8 in Appendix A). In addition, such questions should be assigned to a measurement scale, using as a quality instrument a checklist, a quality scale, or both, when there is no simple answer (Yes/No). In this work, all 52 questions answered with "Yes/No" were used. 


\section{The Kampenes Approach}

The quality evaluation checklist for SE experiments proposed by Kampenes (2007) (Appendix B) contains 26 questions of dichotomous responses, divided into subjects, experimental setting, design and analysis and validity/limitations, in which the objective is to help improving the integrity of the experimental reports in SE (see Table 9 in Appendix B).

\section{The Kitchenham et al. Approach}

The quality evaluation checklist for SE experiments proposed by Kitchenham et al. (2010) (Appendix C) contains 9 questions, where each question has subcategories: (i) "Questions on Aims", (ii) "Questions on Design, Data Collection and Data Analysis" and (iii) "Questions on Study Outcome" totaling 30 sub-questions of dichotomous answers (see Table 10 in Appendix C). The answer to each question is given by a four-point scale: $4=$ all questions listed in the "consider" column can be answered with "yes"; 3 = the majority of all (but not all) questions listed in the "consider" column can be answered with "yes"; 2 = some (but the minority) of the questions listed in the "consider" column can be answered with "yes" and $1=$ none of the questions listed in the "consider" column can be answered with "yes". At the end, a final score is added to each of the 9 questions.

\section{The Dieste et al. Approach}

The quality scale to evaluate for SE experiments proposed by Dieste et al. (2011) (Appendix D) contains 10 questions of dichotomous answers based on five dimensions: Experimental context, experimental design, analysis, presentation of results and interpretation of results (see Table 11 in Appendix D). At the end, a global quality score is the percentage of "yes" responses obtained by the experiment in relation to the total of evaluated questions, as presented in the Formula 1. Experiments with a global score close to $1.0(100 \%)$ are high quality experiments. When the score is near 0.0 $(0 \%)$, the experiments are considered low quality:

$$
\text { Quality score }=\frac{\text { Number_of_yeses }}{\text { Number_of_yeses }+ \text { Number_of_nos }}
$$

\section{Software Product Lines}

An SPL is a set of products that address a particular market segment or a particular mission (Clements and Northrop, 2002). This set of products is also called the product family, in which the members of this family are specific products generated from the reuse of a common infrastructure, named core assets.

The core assets is composed of a set of common characteristics (similarities) and variable characteristics (variabilities) (Linden et al., 2007). This core forms the basis of an SPL and includes the Product-Line Architecture (PLA), reusable components, domain models, requirements assets, test plans and feature and variability models.

The PLA is one of the most important SPL artifacts (Linden et al., 2007), because it represents the abstraction of all possible product-specific architectures generated from such SPL. Some important PLA requirements are (Medvidovic and Taylor, 2010): to remain stable over the life of SPLs, suffering as few changes as possible; easy integration of new features during the architecture lifecycle; and explicitly represent the variations to provided for reuse.

The feature model contains all the features of an SPL and their interrelationships. According to Apel et al. (2013a), a feature is a characteristic or end-user-visible behavior of a software system. A feature may be mandatory, optional or alternative.

The feature model represents the SPL variabilities (Apel et al., 2013a). Variabilities are described by: Variation point that allows the resolution of variabilities in SPL generic artifacts; Variant represents the possible elements that can be chosen to solve a variation point; Constraints between variants establish the relationships between one or more variants in order to solve their respective variation points or variability in a given binding time (Halmans and Pohl, 2003; Linden et al., 2007; Pohl et al., 2005).

Variability is essential for an SPL, as it represents how members of a family of certain products can distinguish themselves from each other (Weiss and Lai, 1999). Thus, a variability can be modeled to allow the development of custom products by configuring and tuning reusable artifacts for a particular context (Pohl et al., 2005).

In this context, Pohl et al. (2005) developed the SPL engineering framework, which aims to incorporate the core concepts of traditional product-line engineering, providing artifact reuse and mass customization throughout variability. This framework is divided into two processes with their respective subprocesses and artifacts, as shown in Fig. 1 (Pohl et al., 2005).

In the Domain Engineering process, the similarities and variabilities of SPLs are identified and realized. This is composed of five main subprocesses: Product Management deals with the SPL scope and its market strategies; Domain Requirements Engineering addresses the elicitation and documentation of SPL requirements; Domain Design defines the SPL reference architecture used in the Application Design; Domain Realization deals with the design and implementation of common assets; and Domain Testing performs the validation and verification of reusable components. 


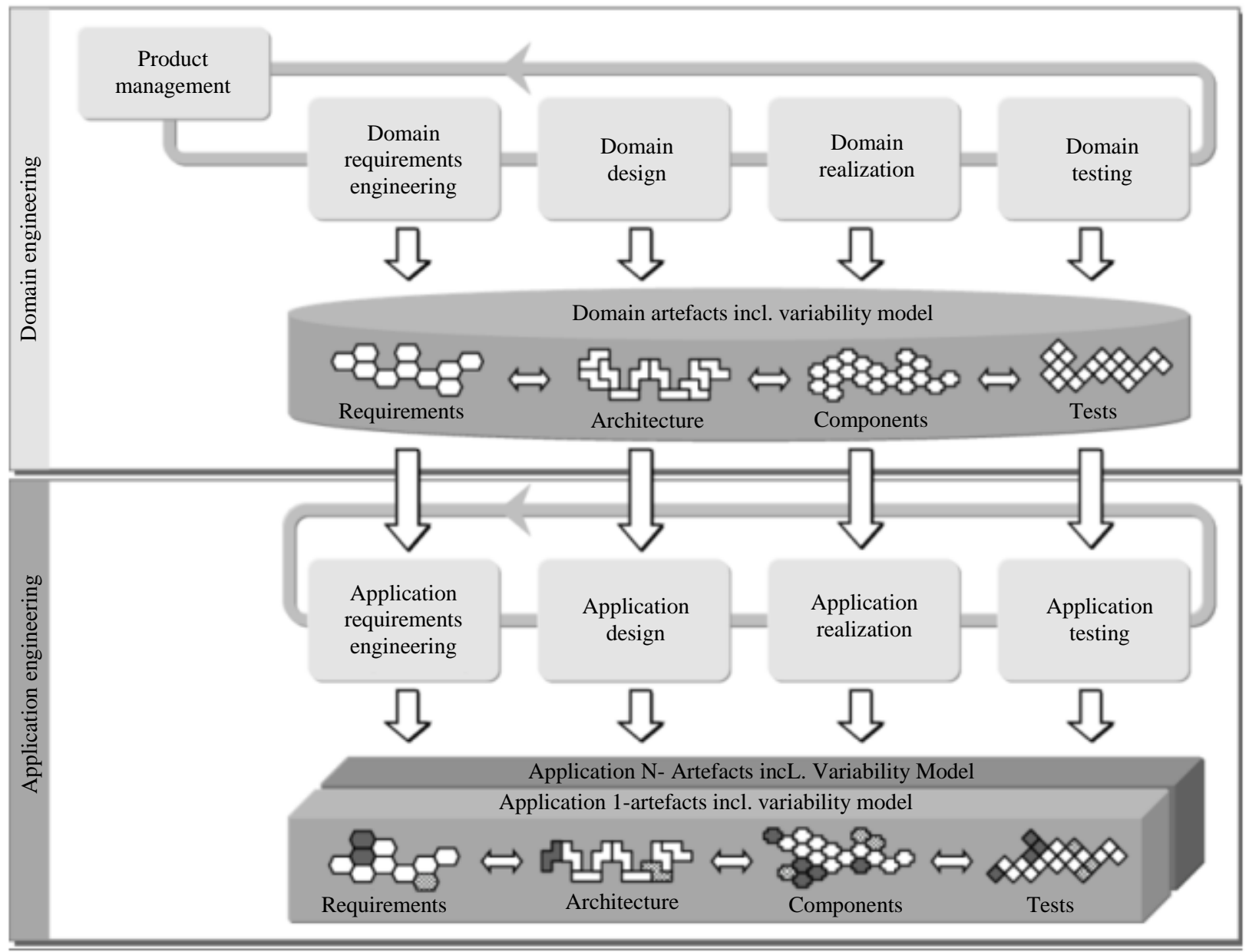

Fig. 1: The SPL engineering framework (Pohl et al., 2005)

As for the Domain Engineering artifacts that form the SPL platform and are stored in the same repository, we have: The variability model that presents the variation points and their variants, besides defining the dependencies and constraints; the requirements that are textual or model-based, which they are common to all applications and variables, allowing the derivation of customizable requirements for different applications; the PLA that defines the structure (static and dynamic decomposition that is valid for all SPL products) and the texture (set of common rules for designing and realizing the parts and their combinations to form the applications) of the SPL products; the components that are configurable and perform variability by means of appropriate parameters in its interface; and tests that contain the test plan, test cases and test case scenarios to assist in executing them.

In the Application Engineering process, products of an SPL are built by reusing domain artifacts and exploring variabilities. This process is composed of subprocesses: Application Requirements Engineering deals with the specification of the application requirements; Application Design derives the product architecture; Application Realisation makes the implementation of the products using assets of the subprocess of accomplishment of the domain to reduce the time and effort; and Application Testing to validate and verify the derived product.

With relation to the Application Engineering artifacts, they include: The variability model that documents the linkage of variability with its justification of selection for a specific application, in addition to being limited by the dependencies and constraints of variability determined in the domain variability model; the requirements that present the complete specification of the product, including reusable and applicationspecific requirements; the PLA of the product that is a specific instance of the domain architecture; the components of a specific product configured by parameters; and tests that document a given product in a traceable and repeatable way. 


\section{Experimentation in SPL}

In this section we summarize a Systematic Mapping (SM) study conducted following the guidelines proposed in Kitchenham et al. (2015) and Petersen et al. (2015) to identify SPL experiments in the literature. A paper on this SM study is currently submitted to a journal.

For this, the search string presented in Table 1 was applied, in which it was adapted according to each data source.

The search for primary studies involved two stages: the first, an automatic search in 5 data sources (IEEE, ACM, ScienceDirect, Scopus and Springer) returned 909 documents; and second, a manual search in 15 Conferences and 11 journals of related areas, such as IET Software, Empirical Software Engineering, IEEE Software, IST, JSS, Empirical Software Engineering and Measurement (ESEM), Brazilian Symposium on Software Engineering (SBES), Evaluation and Assessment in Software Engineering (EASE) and Software Product Line Conference (SPLC) returned 130 documents. We obtained 1.039 primary studies. Filters and results of the process are shown in Fig. 2.

The primary studies selection was initially performed by reading the title, abstract and keywords, in which the inclusion and exclusion criteria were applied. After performing such reading, 219 duplicate studies and 553 studies that did not address SPL experiments were excluded, thus, 267 potential studies were selected.

Then, the selected primary studies were fully read and inclusion and exclusion criteria was applied again. Thus, 94 studies were excluded and a study that addressed a replicated experiment and quoted the original experiment, but the latter was not included in the initial set of studies, thus this study was included later. Therefore, 174 studies were selected for the application of quality assessment criteria (see Table 12 in Appendix E).

During quality assessment, we observed 89\% (155) obtained high quality, $11 \%$ (19) had medium quality and none $(0 \%)$ low quality, confirming the relevance and credibility of the selected studies. Thus, a final set of 174 primary studies were selected, presented in Appendix A.

As for the analysis carried out in these studies, we observed SPL experiments are on testing, architecture design optimization and feature model configuration domain, for example. With regard to the main artifacts we obtained feature model, SPL documentation, test cases, class diagrams and use cases, source code, among others. Choice and size of SPL, participants experience and number of SPL architecture were the most discussed threats to validity.

\section{Related Work}

To the best of our knowledge, no studies were found related to this empirical study, neither for comparing the SE experiment quality evaluation approaches nor for the SPL context.

Table 1: General search string

\section{"software"}

AND

("product line" OR "product lines" OR "product-line" $\mathbf{O R}$ "productlines" OR "product line engineering" $\mathbf{O R}$ "productfamily" OR "product-families" OR "product family" OR "product families" OR "family of products")

AND

("experiment" OR "experiments" OR "experimental" OR

"experimentation" OR "controlled experiment” OR

"controlled experiments" OR "quasi-experiment" OR “quasi-experiments" OR "quasi-experimental” OR "quasi-experimentation")

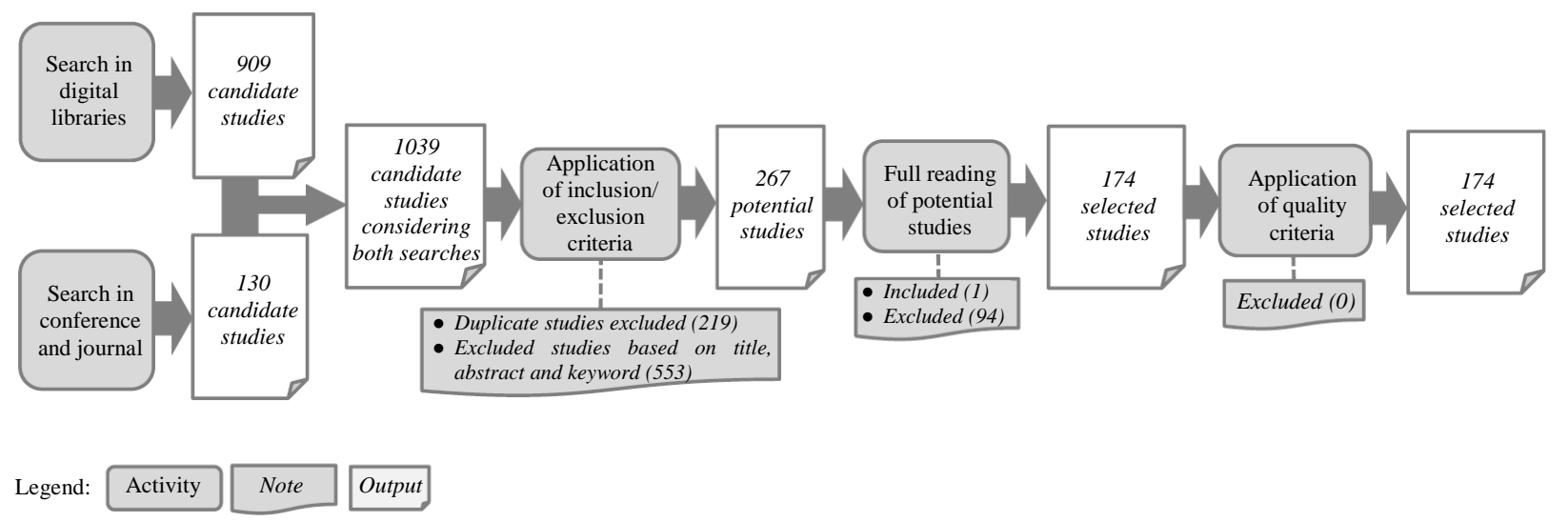

Fig. 2: Filters and results of the SM primary study selection process 


\section{Empirical Study}

This section reports the empirical study carried out.

\section{Study Planning}

Goals

Based on the Goal-Question-Metric (GQM) model (Basili and Rombach, 1988), the empirical study objective was: Compare approaches of quality evaluation of experiments in SE, with the purpose of evidencing, with respect to the capability to report SPL experiments, from the point of view of SPL researchers, in the context of graduate students of the SE area from the State University of Maringá (UEM).

The main goal of our empirical study can be established in the following Research Question (R.Q.): "What is the best approach for reporting SPL experiments based on approaches for quality evaluation of experiments in SE?"

\section{Participants}

The participants in this study were the first three coauthors of this paper. Thus, a random selection was not performed. All the people involved in this project are master's students in the Graduate Program in Computer Science of the State University of Maringá (UEM). The first coauthor has experience with SE experiments for about two and a half years, while the second and third coauthors have been around for 1 year. Although the participants had low experience in SE experimentation, they were considered eligible to act as quality participants of the papers assessed in this study, due to the fact that they were under the supervision of Prof. Dr. Edson OliveiraJr and they attended a 1-semester Experimental SE graduate course.

\section{Experimental Units}

There is one main experimental unit involved in this empirical study: A set of 30 papers that discuss SPL experiments. This number of papers was chosen because it is considered the minimum adequate value for statistical analysis and because the evaluation approaches have so many questions. The selected papers are a subset of SM primary studies (Section 2.3). From the 174 SM papers, 30 papers were selected from a random function provided by Microsoft Excel ${ }$, which was sufficient to ensure that the selection of the papers was not intentional.

\section{Material}

The material used in this study were an Excel spreadsheet with the four approaches to quality evaluation of SE experiments.

Tasks

In this study each participant acted as a evaluator and evaluated each of the 30 papers using the following approaches to determine quality: A1 (Kitchenham and Charters, 2007) checklist, A2 (Kampenes, 2007) checklist, A3 (Kitchenham et al., 2010) checklist and A4 Dieste et al. (2011) quality scale.

\section{Variables}

Table 2 describes the dependent and independent variables of our study. Its has the abbreviation "N.A." (Not Available) used when there is no such information.

The independent variables were the approaches for quality evaluation of experiments in SE: A1, A2, A3 and $\mathrm{A} 4$.

The dependent variables were:

- Quality of experiments: Represents the quality of reporting of each SPL experiment for each approach

- Usage of templates for experimental reporting: Represents the quality of each SPL experiments for each approach when using or not using an experimental template for reporting

- Granularity of questions from the approaches: Represents the quality of each SPL experiment for each approach divided into experimental phases proposed by Wohlin et al. (2012)

This variables contribute to identify the best quality evaluation approach for reporting SPL experiments because three dependent variables deal with reporting quality aspects of the experiments, in which the first one is more generally, the second relates to the use of experimental template and the last one in a more specific way by experimental phase, since each approach categorized their questions with names similar to experimental phases.

Table 2: Dependent and independent variables description

\begin{tabular}{|c|c|c|c|c|c|c|c|c|c|}
\hline Name of variable & $\begin{array}{l}\text { Type of the variable } \\
\text { (independent, } \\
\text { dependent, } \\
\text { moderating) }\end{array}$ & Abbreviation & $\begin{array}{l}\text { Class (product, } \\
\text { process, } \\
\text { resource, } \\
\text { method) }\end{array}$ & $\begin{array}{l}\text { Entity } \\
\text { (instance of } \\
\text { the class) }\end{array}$ & $\begin{array}{l}\text { Type of } \\
\text { Attribute } \\
\text { (internal, } \\
\text { external,...) }\end{array}$ & $\begin{array}{l}\text { Scale type } \\
\text { (nominal, } \\
\text { ordinal,...) }\end{array}$ & Unit & Range & Counting rule \\
\hline $\begin{array}{l}\text { Approaches for quality } \\
\text { Evaluation of } \\
\text { Experiments in SE }\end{array}$ & Independent & N.A. & Method & $\begin{array}{l}\mathrm{A} 1, \mathrm{~A} 2 \\
\mathrm{~A} 3 \text { and } \mathrm{A} 4\end{array}$ & N.A. & Nominal & N.A. & $\begin{array}{l}\mathrm{A} 1, \mathrm{~A} 2 \\
\mathrm{~A} 3 \text { and } \mathrm{A} 4\end{array}$ & N.A. \\
\hline Quality of Experiments & Dependent & N.A. & Process & $\begin{array}{l}\text { Weak, Moderate, } \\
\text { Strong, Positive, } \\
\text { Negative }\end{array}$ & External & Nominal, ordinal & $\begin{array}{l}\text { Correlation } \\
\text { scale }\end{array}$ & {$[-1.0,+1.0]$} & $\begin{array}{l}\text { Pearson (p) } \\
\text { formula }\end{array}$ \\
\hline $\begin{array}{l}\text { Granularity of Questions } \\
\text { from the Approaches }\end{array}$ & Dependent & N.A. & Process & & External & & & $\begin{array}{l}\text { Between } 0 \\
\text { and } 1\end{array}$ & $\begin{array}{l}\text { Dieste } \text { et al. } \\
\text { formula }\end{array}$ \\
\hline
\end{tabular}




\section{Design}

We used one factor with more than two treatments design, in which the treatments are compared to each other (Wohlin et al., 2012). The factor in this study is the approaches for quality evaluation of experiments in SE and the treatments are: A1, A2, A3 and A4.

\section{Procedure}

For each participant the same 30 selected papers were assigned not randomly. For each paper, the participant answered questions in the A1, A2, A3 and A4 approaches. Each question or sub-question was answered with "yes" or "no". For each "yes" answer, the participants had the task of writing an observation that contained the page, section and/or paragraph in which the information was contained, in addition to noting the response time for each approach.

\section{Analysis Procedure}

After completing the answers in the spreadsheet of papers versus approaches, Kappa (Fleiss et al., 2003) agreement analysis was performed with the support of a tool (2Available

at
http://www.lee.dante.br/pesquisa/kappa/index.html.

Accessed on 10/09/2018) developed by the Laboratory of Epidemiology and Statistics (Lee) of the Dante Pazzanese Institute of Cardiology to verify the agreement between the 3 participants.

Finally, a consensus was made between the participant's assessments of the responses of the approaches in each paper to subsequently obtain the quality of experiments, the usage of templates for experimental reporting and the granularity of questions from the approaches.

\section{Execution}

\section{Preparation}

Before starting the our empirical study, a pilot project was performed, in which the participants selected 2 random papers: Michalik et al. (2011a) and Murashkin et al. (2013a), which are not included in the 30 papers of the study, to calibrate and equalize the evaluation form of each participant.

For this preparation, the participants carried out the evaluation of each of the 2 papers together for the 4 proposed approaches in order to solve possible doubts with regard to the interpretation of questions.

\section{Deviations}

During the execution of our study, there were no deviations with regard to the planned instrumentation and the collection process. In addition, none of the participants dropped out of the study.

\section{Analysis}

We present the analysis of our empirical study in this section, initially with the Kappa agreement analysis, the quality of experiments, the usage of templates for experimental reporting and the granularity of questions from the approaches.

\section{Kappa Agreement Analysis}

To evaluate the level of agreement between the 3 participants, in relation to the answers obtained from the four approaches applied in the 30 papers, we performed the Kappa statistical test (Fleiss et al., 2003) and to get to know whether the results would be satisfactory or not we based on the interpretation proposed by Fleiss et al. (2003), as shown in the Table 3.

Table 4 presents the results obtained with the application of the coefficient Kappa for each approach in relation to the 30 papers.

Table 3: Interpretation of Kappa values proposed by (Fleiss et al., 2003)

\begin{tabular}{ll}
\hline Kappa values & Strength of Agreement \\
\hline$<0.40$ & Poor agreement \\
$0.40-0.75$ & Fair to good agreement \\
$>0.75$ & Excellent agreement \\
\hline
\end{tabular}

Table 4: Results of the Kappa Coefficient for each Paper (P) and Approach (A1 through A4)

\begin{tabular}{|c|c|c|c|c|}
\hline Paper ID & $\mathrm{A} 1$ & $\mathrm{~A} 2$ & $\mathrm{~A} 3$ & $\mathrm{~A} 4$ \\
\hline $\mathrm{P} 1$ & 0.490 & 0.479 & 0.509 & 0.144 \\
\hline $\mathrm{P} 2$ & 0.583 & 0.422 & 0.422 & 0.607 \\
\hline P3 & 0.466 & 0.490 & 0.466 & 0.365 \\
\hline P4 & 0.433 & 0.328 & 0.186 & 0.345 \\
\hline P5 & 0.350 & 0.061 & 0.244 & 0.029 \\
\hline P6 & 0.308 & 0.458 & 0.507 & 0.492 \\
\hline P7 & 0.461 & 0.443 & 0.598 & 0.151 \\
\hline P8 & 0.436 & 0.597 & 0.432 & 0.542 \\
\hline P9 & 0.280 & 0.554 & 0.220 & 0.112 \\
\hline P10 & 0.477 & 0.498 & 0.293 & -0.179 \\
\hline P11 & 0.438 & 0.527 & 0.630 & 0.139 \\
\hline P12 & 0.193 & 0.490 & 0.278 & 0.340 \\
\hline $\mathrm{P} 13$ & 0.435 & 0.810 & 0.626 & 0.340 \\
\hline P14 & 0.374 & 0.409 & 0.482 & -0.138 \\
\hline P15 & 0.562 & 0.434 & 0.499 & 0.083 \\
\hline P16 & 0.562 & 0.434 & 0.499 & 0.083 \\
\hline P17 & 0.562 & 0.434 & 0.499 & 0.083 \\
\hline P18 & 0.661 & 0.683 & 0.460 & 1.000 \\
\hline P19 & 0.793 & 0.742 & 0.821 & 0.345 \\
\hline P20 & 0.654 & 0.519 & 0.656 & 0.505 \\
\hline $\mathrm{P} 21$ & 0.405 & 0.639 & 0.644 & 0.591 \\
\hline $\mathrm{P} 22$ & 0.422 & 0.494 & 0.814 & 0.340 \\
\hline $\mathrm{P} 23$ & 0.610 & 0.685 & 0.686 & 0.591 \\
\hline P24 & 0.462 & 0.647 & 0.386 & 0.365 \\
\hline P25 & 0.472 & 0.473 & 0.400 & 0.637 \\
\hline P26 & 0.584 & 0.507 & 0.545 & 0.628 \\
\hline P27 & 0.381 & 0.771 & 0.333 & -0.031 \\
\hline P28 & 0.579 & 0.682 & 0.408 & 0.393 \\
\hline P29 & 0.508 & 0.647 & 0.666 & 0.293 \\
\hline P30 & 0.340 & 0.494 & 0.358 & 0.158 \\
\hline
\end{tabular}




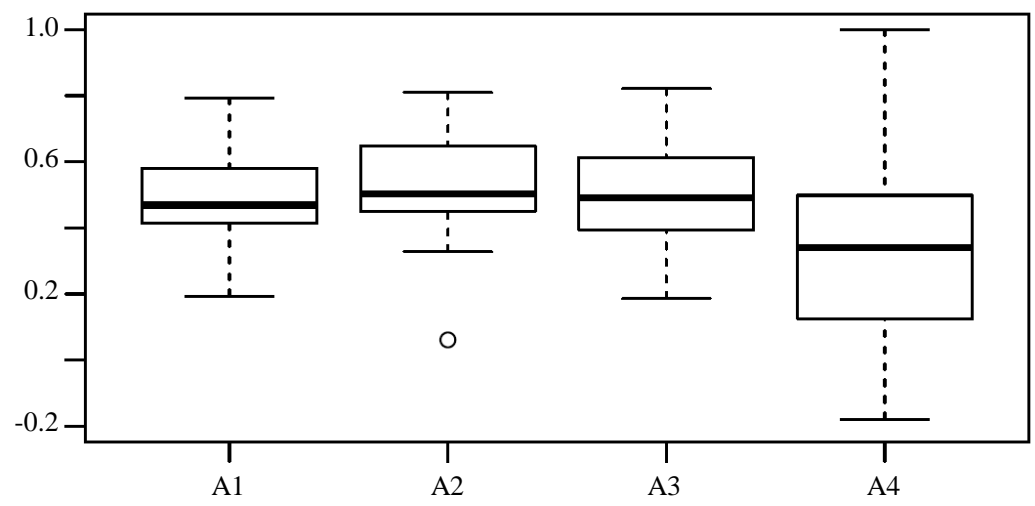

Fig. 3: Box plot for the Kappa values of each approach

As it can be seen in Fig. 3, the median shows a very close agreement between A1, A2 and A3 approaches, which are close to 0.4 and 0.5 indicating a fair to good agreement between the answers of the 3 participants for these approaches. Except for a disparity in the A2 approach (P5, 0.061) considered an outlier that was maintained in the analysis. For the A4 approach, the median was below 0.4, indicating a poor agreement among the participants.

\section{Quality of Experiments}

After analyzing the degree of agreement between the answers, the 3 participants reached a consensus for a single answer on each question of each of the four approaches in the 30 papers under study. To do so, when the response of two participants was: "yes", the final answer was "yes"; and "no", the final answer was "no". In the case where only one of the participants disagreed in the response, a discussion was held among the participants to reach a final answer.

Shortly after obtaining a single answer for each question in the 30 papers in each approach, it was possible to obtain the final quality score of the four approaches, as presented in Table 5. For this, in the approaches A1, A2 and A4 we used the Formula 1 (Section 2.1.4) proposed by Dieste et al. (2011), where it is composed of the number of "Yes" responses divided by the number of "Yes" responses added to the number of "No" responses. Whereas for the A3 approach, because the answers to the questions are given by a four-point scale, we applied the Formula 2, in which the sum of the 9 questions divided by 36 is made (which is the maximum value of the summation, that is, 9 (questions) * 4 (when all answers of the subquestions are "yes")), getting a value between 0 and 1, just as the result of the Formula 1:

Quality score $=\frac{\Sigma \text { Questions }}{36}$

Thus, the final quality score obtained in each approach (Table 5) was used to calculate the correlation between pairs of approaches. Based on this, the following hypotheses were stated:

- Null Hypothesis ( $\left.\mathbf{H}_{0}\right)$ : There is no significant correlation between the $\mathrm{X}$ and $\mathrm{Y}$ approaches for evaluating the quality of SPL experiments

- Alternative Hypothesis $\left(\mathbf{H}_{1}\right)$ : There is significant correlation between the $\mathrm{X}$ and $\mathrm{Y}$ approaches for evaluating the quality of SPL experiments

$\mathrm{X}$ and $\mathrm{Y}$ are replaced with each pair of approaches in this study.

As this variable is continuous, we applied the parametric correlation method of Pearson using the statistical tool R (R Core Team, 2014). This method allows to establish whether there is a correlation between two sets of data, represented by $\rho$, which assumes value between -1 and 1, as shown in Fig. 4.

Thus, the following values for $\rho$ were obtained for the correlations:

- $\operatorname{Corr}(A 1$ and A2): $\rho=\mathbf{0 . 7 8 0}$ - Strong positive correlation

- $\operatorname{Corr}(A 1$ and A3): $\rho=\mathbf{0 . 8 3 0}$ - Strong positive correlation

- $\operatorname{Corr}(A 1$ and A4): $\rho=\mathbf{0 . 7 8 3 ~ - ~ S t r o n g ~ p o s i t i v e ~}$ correlation

- $\operatorname{Corr}(A 2$ and A3): $\rho=\mathbf{0 . 8 8 3}$ - Strong positive correlation

- $\operatorname{Corr}(A 2$ and A4): $\rho=\mathbf{0 . 8 4 2}$ - Strong positive correlation

- $\operatorname{Corr}(A 3$ and A4): $\rho=\mathbf{0 . 8 0 0}$ - Strong positive correlation

Based on the correlations, there is initial evidence to reject the null hypothesis $\left(\mathrm{H}_{0}\right)$ of our study and accept the alternative hypothesis $\left(\mathrm{H}_{1}\right)$ (Section 3.3.2), which affirms there is a significant correlation between the approaches for quality evaluation of SPL experiments. 


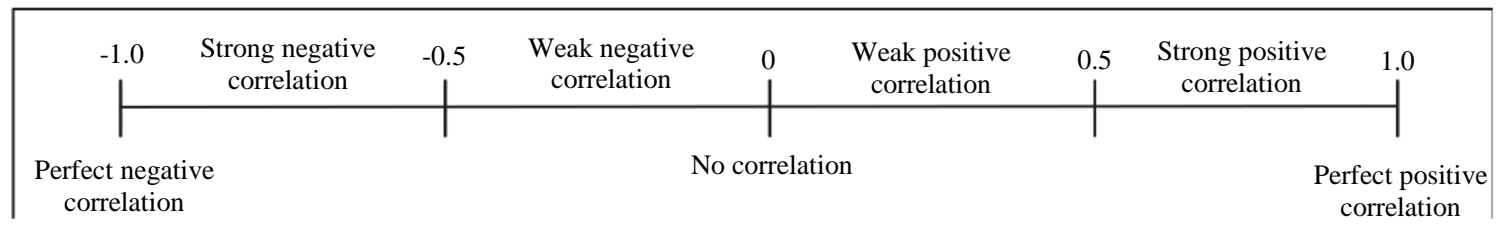

Fig. 4: Pearson correlation scale

Table 5: Final quality score of the papers $(\mathrm{P})$ by approach (A1 through A4) after Kappa analysis

\begin{tabular}{lllll}
\hline Paper ID & A1 & A2 & A3 & A4 \\
\hline P1 & 0.385 & 0.692 & 0.778 & 0.455 \\
P2 & 0.462 & 0.654 & 0.750 & 0.364 \\
P3 & 0.519 & 0.731 & 0.722 & 0.636 \\
P4 & 0.327 & 0.308 & 0.472 & 0.364 \\
P5 & 0.558 & 0.731 & 0.778 & 0.364 \\
P6 & 0.558 & 0.808 & 0.778 & 0.455 \\
P7 & 0.596 & 0.731 & 0.778 & 0.545 \\
P8 & 0.269 & 0.231 & 0.583 & 0.182 \\
P9 & 0.635 & 0.731 & 0.750 & 0.636 \\
P10 & 0.250 & 0.115 & 0.528 & 0.091 \\
P11 & 0.500 & 0.577 & 0.667 & 0.364 \\
P12 & 0.269 & 0.385 & 0.556 & 0.182 \\
P13 & 0.500 & 0.769 & 0.778 & 0.545 \\
P14 & 0.288 & 0.192 & 0.500 & 0.091 \\
P15 & 0.500 & 0.615 & 0.778 & 0.545 \\
P16 & 0.212 & 0.346 & 0.528 & 0.091 \\
P17 & 0.442 & 0.500 & 0.694 & 0.455 \\
P18 & 0.231 & 0.423 & 0.611 & 0.273 \\
P19 & 0.365 & 0.577 & 0.667 & 0.364 \\
P20 & 0.154 & 0.269 & 0.444 & 0.182 \\
P21 & 0.231 & 0.615 & 0.639 & 0.364 \\
P22 & 0.346 & 0.346 & 0.694 & 0.455 \\
P23 & 0.154 & 0.308 & 0.500 & 0.273 \\
P24 & 0.519 & 0.769 & 0.722 & 0.545 \\
P25 & 0.250 & 0.154 & 0.528 & 0.000 \\
P26 & 0.346 & 0.654 & 0.694 & 0.545 \\
P27 & 0.154 & 0.385 & 0.500 & 0.182 \\
P28 & 0.135 & 0.308 & 0.500 & 0.182 \\
P29 & 0.231 & 0.462 & 0.611 & 0.182 \\
P30 & 0.288 & 0.615 & 0.750 & 0.364 \\
\hline
\end{tabular}

Figure 5 presents the scatter plots of the pairs of approaches, emphasizing that all have a positive trend line, confirming the rejection of the null hypothesis $\left(\mathrm{H}_{0}\right)$. Thus, the obtained values of the correlations show the four approaches produce similar results.

Figure 6 presents the quality of the SPL experiments based on the final score of the papers after evaluation in each of the selected approaches. It is possible to observe that the A3 approach obtained the quality of the experiments with a final score of close to 0.7. We understand $\mathrm{A} 3$ has more objective questions and the information regarding its questions is more present in the papers analyzed.

\section{Usage of Templates for Experimental Reporting}

In the 30 experiments selected, we checked whether they adopted any experimental template by referencing the paper that followed the guidelines or the structure of the experiment when they did not explicitly state. Of the 30 papers, only 13 papers used experimental template: 11 papers used by Wohlin et al. (2012), one paper by Kitchenham et al. (2002) and one paper by Jedlitschka et al. (2008). Based on this, the following hypotheses were stated:

- Null Hypothesis $\left(\mathbf{H}_{0}\right)$ : There is no significant difference in the quality of SPL experiments when using an experimental template

- Alternative Hypothesis $\left(\mathbf{H}_{1}\right)$ : There is significant difference in the quality of SPL experiments when using an experimental template

We applied the Kolmogorov-Smirnov normality test for both samples in each of the approaches: using and not using experimental template. We obtained the following results:

- For A1: (i) using template, sample size (N) 13, mean ( $\mu$ ) 0.4053 , standard deviation $(\sigma) 0.1264$, we obtained $p=0.9027$, i.e., with $\alpha=0.05$ (0.9027 > 0.361 ), the sample is normal; and (ii) not using template, sample size $(\mathbf{N})$ 17, mean $(\boldsymbol{\mu})$ 0.3179, standard deviation $(\sigma) 0.1563$, we obtained $p=$ 0.5479 , i.e., with $\alpha=0.05(0.5479>0.318)$, the sample is normal

- For A2: (i) using template, sample size (N) 13, mean ( $\mu$ ) 0.6242 , standard deviation $(\sigma) 0.1144$, we obtained $p=0.9767$, i.e., with $\alpha=0.05$ (0.9767 > 0.361 ), the sample is normal; and (ii) not using template, sample size $(\mathbf{N})$ 17, mean $(\mu)$ 0.4051, standard deviation $(\sigma) 0.2177$, we obtained $p=$ 0.2698 , i.e., with $\alpha=0.05(0.2698<0.318)$, the sample is not normal

- For A3: (i) using template, sample size (N) 13, mean ( $\mu$ ) 0.7052, standard deviation $(\sigma)$ 0.0617, we obtained $p=0.9282$, i.e., with $\alpha=0.05$ (0.9282 > 0.361 ), the sample is normal; and (ii) not using template, sample size $(\mathbf{N}) 17$, mean $(\mu)$ 0.5948, standard deviation $(\sigma) 0.1207$, we obtained $p=$ 0.2848 , i.e., with $\alpha=0.05(0.2848<0.318)$, the sample is not normal

- For A4: (i) using template, sample size (N) 13, mean ( $\mu$ ) 0.4197, standard deviation $(\sigma) 0.1258$, we 
obtained $p=0.6183$, i.e., with $\alpha=0.05$ (0.6183 > 0.361 ), the sample is normal; and (ii) not using template, sample size $(\mathbf{N})$ 17, mean $(\mu)$ 0.2835,

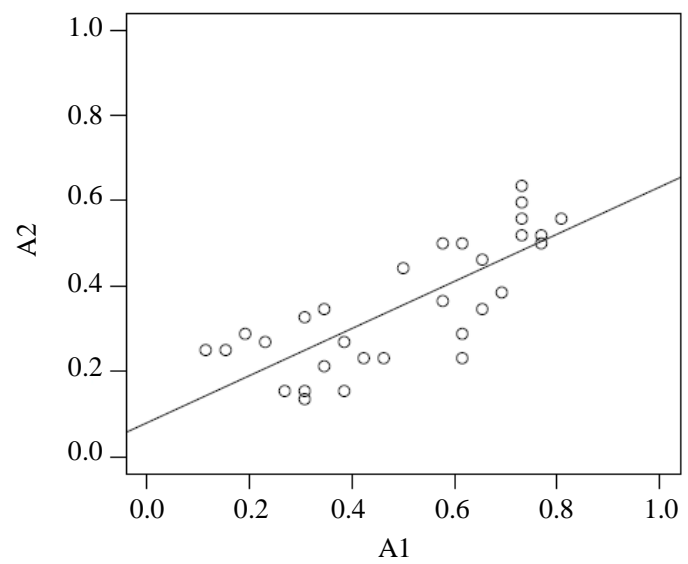

(a)

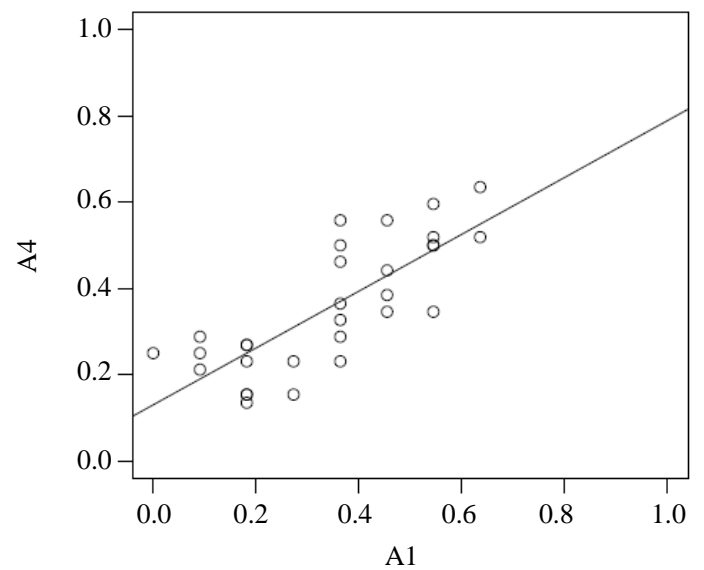

(c)

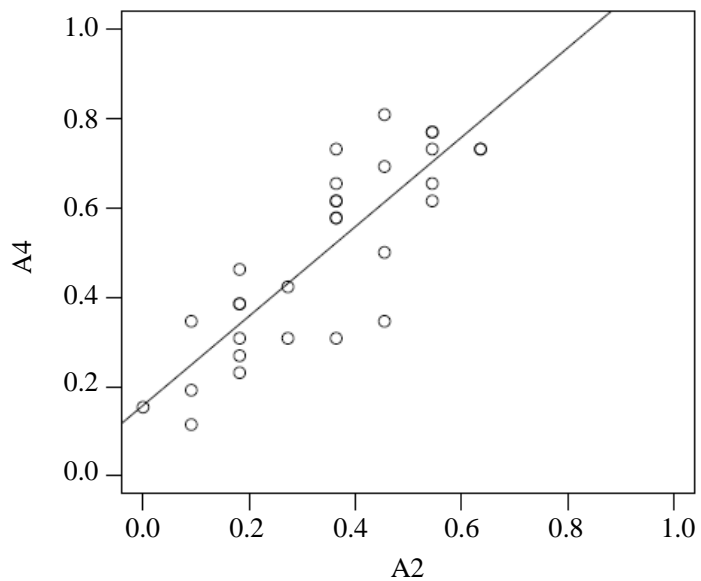

(e) standard deviation $(\sigma) 0.1897$, we obtained $p=$ 0.3139 , i.e., with $\alpha=0.05(0.3139<0.318)$, the sample is not normal

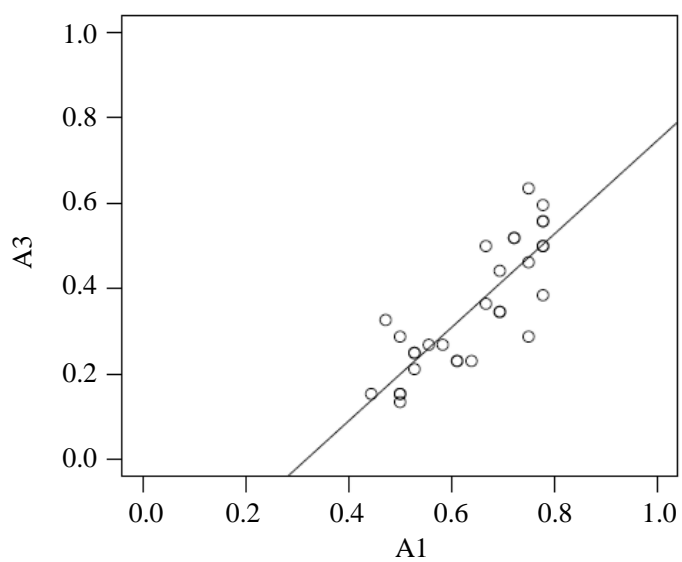

(b)

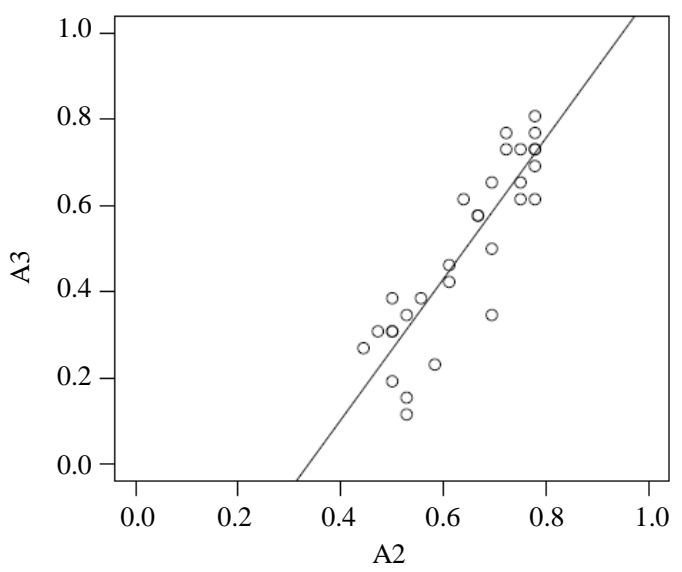

(d)

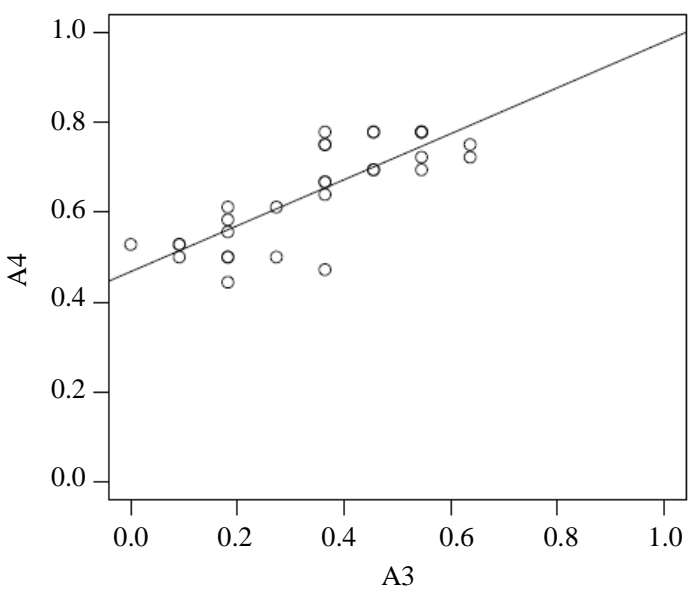

(f)

Fig. 5: Scatter plots of the pair of approaches to the final quality scores; (a) A1 X A2; (b) A1 X A3; (c) A1 X A4; (d) A2 X A3; (e) A2 X A4; (f) A3 X A4 


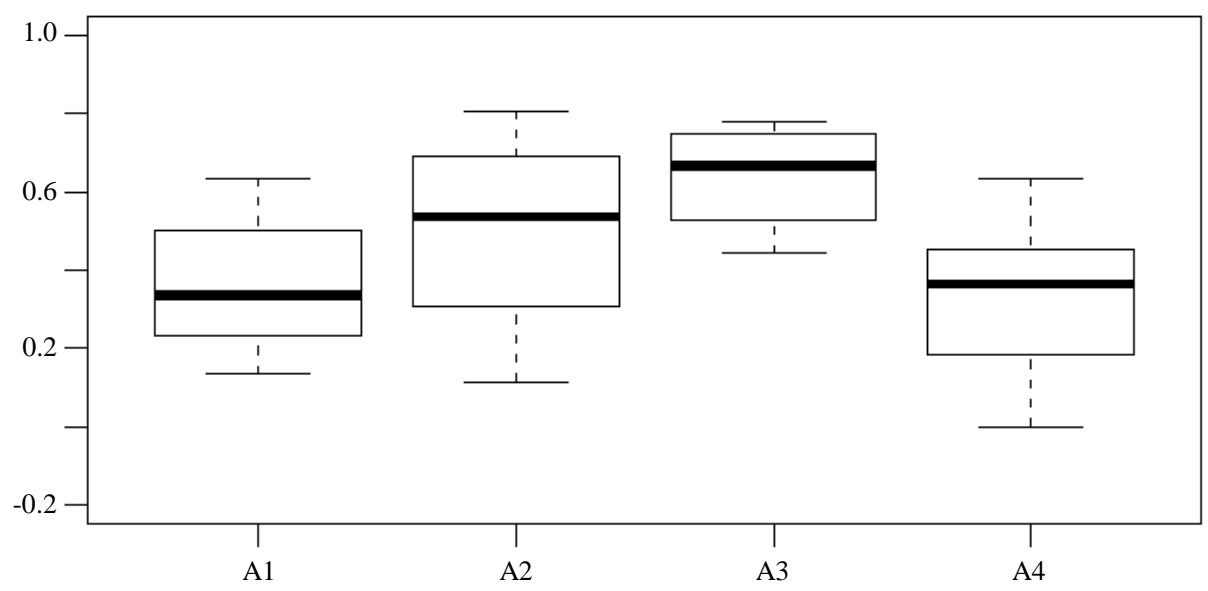

Fig. 6: Box plot for the quality of SPL experiments

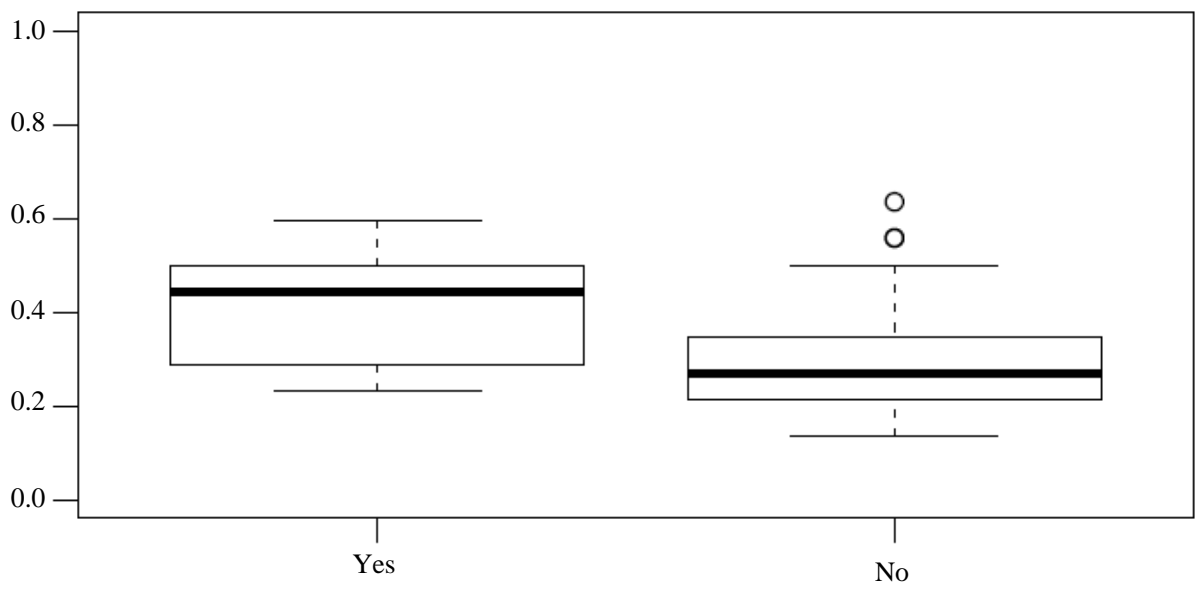

Fig. 7: Box plot for the usage template in A1 approach

In the A1 approach, both samples (using and not using experimental template) are normal, thus we applied the T-Test, obtaining a value for $t_{\text {calculated }}=$ 1.6922 and degree of freedom $(\mathrm{gl})=28$. When searching the index (gl) in the table of critical values of the T-Test, a value for $t_{\text {critical }}=2.05$ was found, with a $(\alpha)$ significance level of 0.05 . Thus, comparing the $t_{\text {critical }}$ with the $t_{\text {calculated, }}$ the null hypothesis could not be rejected $\left(t_{\text {calculated }}(1.6922)<t_{\text {critical }}(2.05)\right)$.

Figure 7 presents the "Yes" and "No" box plots for the usage of experimental template for A1. In the "No" box plot, we see two outliers that were above the median of experimental template, which is a possible evidence of not having rejected the null hypothesis $\left(\mathrm{H}_{0}\right)$. Thus, we remove these two outliers that correspond to three data point from this sample, obtaining a size sample 14 . Then we re-applied the TTest presenting the result for $t_{\text {calculated }}=3.2756$ and degree of freedom $(\mathrm{gl})=23\left(t_{\text {critical }}=2.07\right)$, thus the null hypothesis $\left(\mathrm{H}_{0}\right)$ could be rejected $\left(t_{\text {calculated }}(3.2756)>\right.$ $\left.t_{\text {critical }}(2.07)\right)$. Thus, the result of T-Test was considered, after removal of the outliers in the sample.

A2, A3 and A4 approaches, samples using experimental template $\left(N_{A}\right)$ are normal, but those that do not use experimental template $\left(N_{B}\right)$ are non-normal, thus we applied the Mann-Whitney-Wilcoxon U. In all approaches, the $\left(N_{A}\right)$ sample has 13 data and the $\left(N_{B}\right) 17$ data, so in the table of critical values of that test the value for $U_{\text {critical }}=63$ was found, with a $(\alpha)$ significance level of 0.05 . For the $U_{\text {calculated }}$, the values obtained for the A2, A3 and A4 approaches are shown below:

- $\quad$ For the A2 approach, $U_{\text {calculated }}=46.5$, comparing with the $U_{\text {critical }}$ the null hypothesis $\left(\mathrm{H}_{0}\right)$ could be rejected $\left(U_{\text {calculated }}(46.5)<=U_{\text {critical }}(63)\right)$

- For the A3 approach, $U_{\text {calculated }}=54.5$, comparing with the $U_{\text {critical }}$ the null hypothesis $\left(\mathrm{H}_{0}\right)$ could be rejected $\left(U_{\text {calculated }}(54.5)<=U_{\text {critical }}(63)\right)$ 
- $\quad$ For the A4 approach, $U_{\text {calculated }}=62.5$, comparing with the $U_{\text {critical }}$ the null hypothesis $\left(\mathrm{H}_{0}\right)$ could be rejected $\left(U_{\text {calculated }}(62.5)<=U_{\text {critical }}(63)\right)$

Figure 8 presents the box plots for the papers quality regarding the usage of experimental template in the reporting of the SPL experiments for the four approaches. We can note is the median quality for experiments using experimental template is higher than those that did not use it.

Among the approaches, A2 and A3 were the ones obtained the highest quality using experimental template, in which the final quality score is between 0.6 and 0.7 . Thus, we understand the experimental template influences the quality of the experiments.

Therefore, the T-Test and the Mann-WhitneyWilcoxon $U$ test confirmed that there is a significant difference in

the quality of SPL experiments when using experimental template in the A1, A2, A3 and A4 approaches, which was already expected.

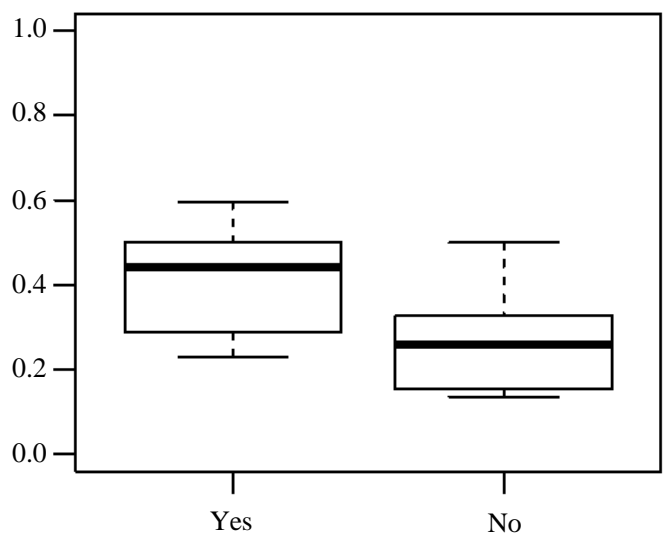

(a)

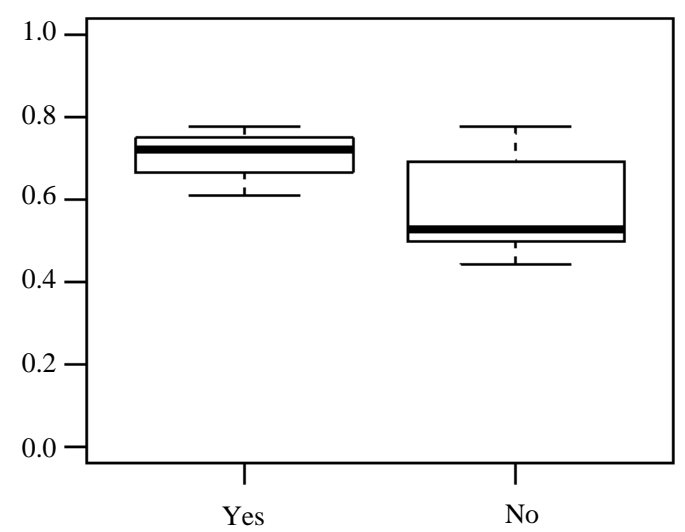

(c)

\section{Granularity of Questions from the Approaches}

We divided the questions from the four approaches for quality evaluation of experiments into four phases, according to Wohlin et al. (2012): Scope, Planning, Execution and Analysis and Interpretation, in order to evaluate their granularity. For each phase, we calculated the quality score in each of the approaches using Formula 1 (Section 2.1.4). For the A3 approach, the questions from 1 to 9 were disregarded because they used a four-point scale and because they did not have the same weights, thus with their subquestions it was possible to apply Formula 1.

Figure 9 presents the granularity of the questions in the planning phase. It is observed that the A2 approach was the one that obtained a score of higher quality, close to 0.6 , whereas the others were close to 0.5 .

Figure 10 presents the granularity of the questions in the analysis and interpretation phase. It is observed that the A3 approach was the one that obtained a quality score of approximately 0.6. Approaches A1 and A4 had a score of quality close to 0.3 and $\mathrm{A} 2$ close to 0.2 .

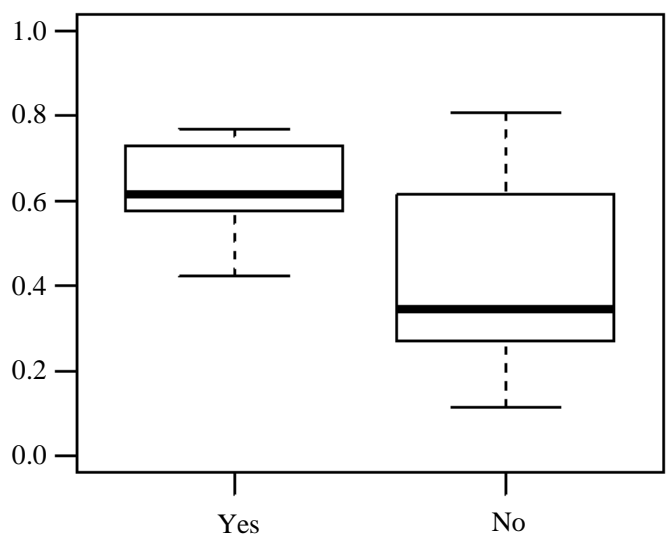

(b)

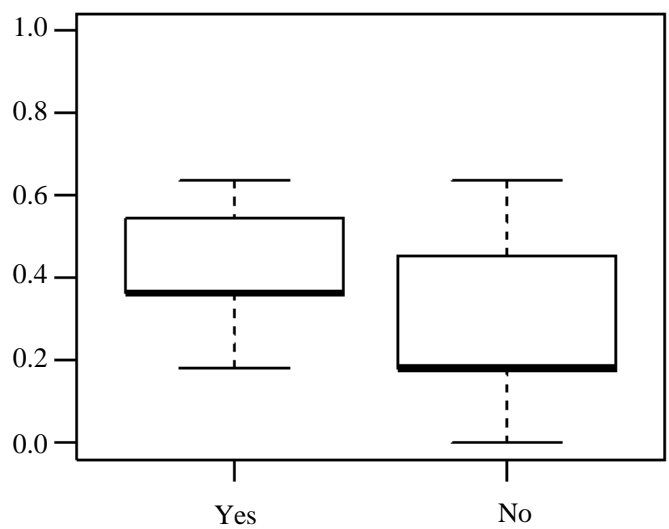

(d)

Fig. 8: Box plot for the usage and non-usage of template in relation to the four approaches; (a) A1 (b) A2 (c) A3 (d) A4 


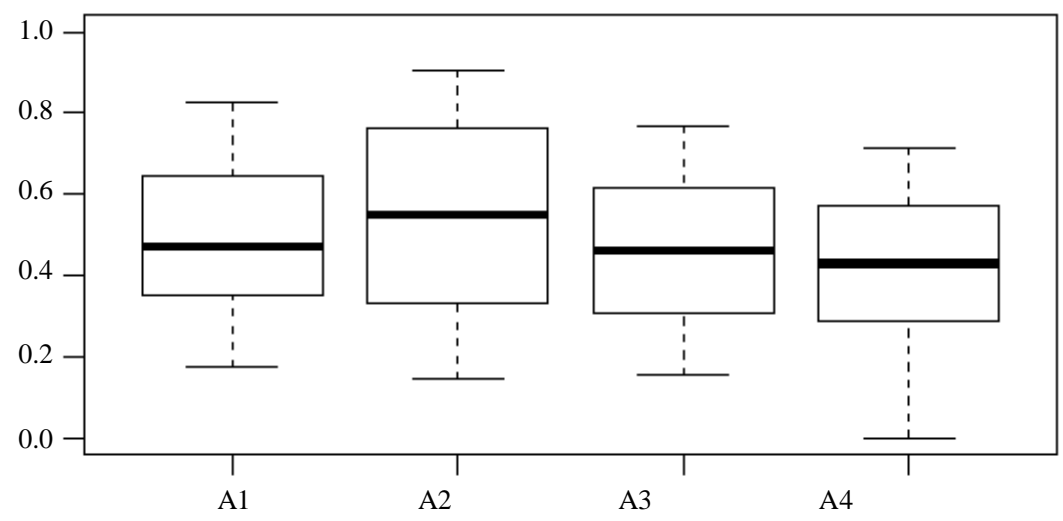

Fig. 9: Box plot for the granularity of questions in the planning phase

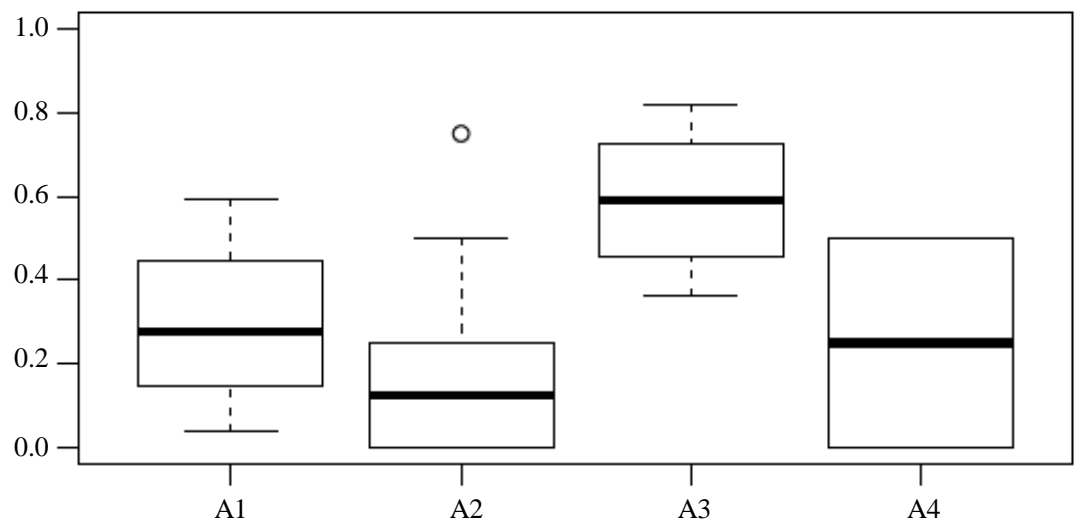

Fig. 10: Box plot for the granularity of questions in the analysis and interpretation phase

The scope and execution phases were those that presented few questions, obtaining a very small sample, therefore, we did not analyze such phases.

When comparing Fig. 9 and 10 with Fig. 6 showing the quality of the SPL experiments in each approach, it is observed that the A1, A2 and A4 approaches obtained a score of higher quality in the planning phase (Fig. 9) and only the A2 approach obtained a score of lower quality in the analysis and interpretation phase (Fig. 10) as presented in Fig. 6. Thus, we understand the SPL experiments report more the planning phase than the analysis and interpretation phase, which also is a phase of paramount importance.

\section{Discussion}

This section provides an overall discussion of the obtained results and implications, as well as threats to validity of the empirical study carried out.

\section{Evaluation of Results and Implications}

With the results obtained in our empirical study and the performed analysis, there is a significant correlation between pairs of approaches for quality evaluation of SPL experiments. This correlation was strongly positive for all pairs of approaches evaluated and was based on three criteria: Quality of experiments, usage of templates for experimental reporting and granularity of questions from the approaches.

The pair of approaches A2 and A3, which obtained the highest correlation with 0.883 compared to the other pairs, was the one that presented the best result in the evaluated criteria. It is possible to observe that the A3 approach was the one that presented the highest score in the "Quality of the experiments", "Granularity of the questions" and the "Usage of templates for experimental reporting".

With regard to the pair of approaches A2 and A4, with correlation 0.842 , such approaches are those that contain fewer questions compared to others, an indication that the results were found in the criterion "Granularity of the questions". In the other two criteria, the A4 approach presented more difference because of the complexity of its questions, with few papers documenting the information needed.

For the pair of approaches A1 and A3, with a correlation of 0.830 . both approaches were developed by Kitchenham with the support of other authors, which 
makes it possible to infer that the results are close to the criteria of "Granularity of the questions" and "Usage of templates for experimental reporting". They differ in the criteria of "Quality of the experiments", because A1 contains 52 questions, which has more questions of all approaches and many of them were not present in the papers being studied, for example, "Did untoward events occur during the study?" and "Is the sample representative of the population to which the results will generalise?".

Considering the pair of approaches A3 and A4, with a correlation of 0.800 , the approaches approximate the criteria of "Granularity of the questions", by having a division of the questions into very similar dimensions. However, they disagree on the other two criteria, because A4 has questions that analyze information not very reported in the papers, for example, "Was randomization used for selecting the population and applying the treatment?" and "Are the statistical significances mentioned with the results?".

With relation to the pair of approaches A1 and A4, with a correlation of 0.783 , these approaches resemble the dimensions that have been divided into their questions, providing evidence for being in the criterion of "Granularity of the questions". Furthermore, they obtained a near-quality score as presented in the "Quality of the experiments" criterion. As for the criterion of "Usage of templates for experimental reporting", A1 presented a score of better quality compared to A4 because of the level of complexity of the A4 approach questions, for example, "Is an appropriate blinding procedure used (e.g., blind allocation of materials, blind marking)?".

In the pair of approaches A1 and A2, which obtained the lowest correlation $(0.780)$, it is observed that in the criterion "Granularity of the questions", both approaches had very close results. With relation to the other criteria, which are based on the quality score obtained from the papers, A2 stands out because it contains more objective questions, for example, "Sample size", "The use of tools" and "Assignment procedure (randomized or quasi)".

\section{Threats to Validity}

The threats to validity identified during this empirical study were categorized into internal, external, construct and conclusion, according to Wohlin et al. (2012).

\section{Internal Validity}

One of the threats was the difference in the knowledge level of the participants, especially in relation to the selected approaches. To minimize this threat, we conducted a bibliographic study of each approach, followed by a pilot project to unify the understanding of each question in each evaluation approach, providing the balance of knowledge necessary to carry out our empirical study.

Another threat was related to the influence of the participants during the study. To minimize such a threat, the spreadsheets that the participants completed were stored locally by each one and were only shared between them after all had been filled out. In addition, each participant worked in their own environment at a time most suitable for him/her.

\section{External Validity}

One of the threats was in relation to the selected participants, since they are master students in the SE area. However, more studies that include researchers with experience in SE Experimental and SPL should be conducted, thus the results can be generalized.

Another threat was the instrumentation used in relation to the heterogeneity of the sample, in which the selected papers obtained a moderate quality, as presented in Fig. 6. Thus, new studies must be conducted, stratifying the experiments with high, moderate and low quality.

\section{Construct Validity}

The dependent variable correlation between the pairs of approaches was calculated according to Pearson. The independent variable approaches for quality evaluation of experiments in $S E$ was guaranteed by the pilot project, in which the participants became familiar with such approaches applied in two papers that were not part of the execution of the study, evaluating the feasibility of the applied approach.

\section{Conclusion Validity}

A threat considered as a risk to affect statistical validity was the sample size $(\mathrm{N}=30)$, mainly in the analysis of the criterion "Usage of templates for experimental reporting", in which such sample was divided into two samples, one with size 13 and the other with 17. Thus, the size of such sample should be increased during prospective replications of this study.

\section{Study Packing and Sharing}

All documents related to the study are available online via the web (https://doi.org/10.5281/zenodo.2575487) in order to promote possible future replications.

\section{Conclusion and Future Work}

The quality evaluation of experiments is fundamental to build a body of reference and reliable knowledge. In this paper, we carried out an empirical study, aiming to compare the existing approaches for quality evaluation of SE experiments, in order to indicate which approach was the best to reporting experiments in the SPL domain, based on three criteria presented in Section 3.1.6.

The Pearson's correlation was used between pairs of approaches, which showed strong positive correlations to analyze the "Quality of experiment". The T-Test and 
Mann-Whitney-Wilcoxon $U$ test were applied to the samples to analyze the "Usage of templates for experimental reporting" to verify whether there was a difference in the quality of the experiments when using an experimental template, in which in which the result was positive. In "Granularity of questions from the approaches" the SPL experiments report more the planning phase.

Therefore, the results obtained provided initial evidence A2 and A3 approaches are the best for reporting SPL experiments.

Directions for future work include planning the internal and external replication of this study to corroborate with the results obtained. Taking into account the actions discussed in Section 3.4.2 to mitigate threats to validity.

\section{Funding Information}

This study was financed in part by the Coordenação de Aperfeiçoamento de Pessoal de Nível Superior Brasil (CAPES) - Finance Code 001.

\section{Author's Contributions}

Viviane F. Furtado, Henrique Vignando and Victor França: Coordinated the experiment performed at the Informatics Department of the State University of Maringá by planning, executing, analyzing and interpreting it. They also contributed in writing this paper.

Edson OliveiraJr: Supervised Viviane, Henrique and Victor during the experiment, contributed to planning, executing, analyzing and interpreting the experiment results. He also contributed in proofreading and writing this paper.

\section{Ethics}

Experiment participants were previously invited, thus they attended such experiments as volunteers. Participants were informed the experiment will contribute to a nonprofit research project coordinated by Dr. Edson OliveiraJr.

\section{References}

Accioly, P., P. Borba and R. Bonifacio, 2012. Comparing two black-box testing strategies for software product lines. Proceedings of the 6th Brazilian Symposium on Software Components Architectures and Reuse, Sept. 23-28, IEEE Xplore Press, Natal, Brazil, pp: 1-10.

DOI: 10.1109/SBCARS.2012.17

Accioly, P.R.G., P. Borba and R. Bonifacio, 2014. Controlled experiments comparing black-box testing strategies for software product lines. JUCS, 20: 615-639.
Acher, M., A. Cleve, G. Perrouin, P. Heymans and C. Vanbeneden et al., 2012. On extracting feature models from product descriptions. Proceedings of the International Workshop on Variability Modeling of Software-Intensive Systems, Jan. 25-27, ACM, Leipzig, Germany, pp: 45-54. DOI: $10.1145 / 2110147.2110153$

Adam, S. and K. Schmid, 2013. Effective requirements elicitation in product line application engineering: An experiment. Proceedings of the International Working Conference on Requirements Engineering: Foundation for Software Quality, Apr. 08-11, Springer, Essen, Germany, pp: 362-378.

DOI: $10.1007 / 978-3-642-37422-7 \_26$

Ahmed, Z., 2007. Measurement analysis and fault proneness indication in Product Line Applications (PLA). Proceedings of the International Conference on New Software Methodologies, Tools and Techniques, (MTT'07).

Akim, C.H.P., S. Khurshid and D. Batory, 2012. Shared execution for efficiently testing product lines. Proceedings of the IEEE 23rd International Symposium on Software Reliability Engineering, Nov. 27-30, IEEE Xplore Press, Dallas, TX, USA, pp: 221-230. DOI: 10.1109/ISSRE.2012.23

Al-Hajjaji, M., S. Krieter, T. Thum, M. Lochau and G. Saake, 2016. IncLing: Efficient product-line testing using incremental pairwise sampling. Proceedings of the International Conference on Generative Programming: Concepts and Experiences, Oct. 31Nov. 01, ACM, Amsterdam, Netherlands, pp: 144-155. DOI: 10.1145/2993236.2993253

Al-Hajjaji, M., T. Thum, J. Meinicke, M. Lochau and G. Saake, 2014. Similarity-based prioritization in software product-line testing. Proceedings of the 18th International Software Product Line Conference Sept. 15-19, ACM, Florence, Italy, pp: 197-206. DOI: 10.1145/2648511.2648532

Al-Msie'deen, R., M. Huchard, A.D. Seriai, C. Urtado and S. Vauttier, 2014. Automatic documentation of [mined] feature implementations from source code elements and use-case diagrams with the REVPLINE approach. Int. J. Software Eng. Knowl. Eng., 24: 1413-1438.

DOI: $10.1142 / \mathrm{S} 0218194014400142$

Almeida, E.S., E.C.R. Santos, A. Alvaro, V.C. Garcia and S.L. Meira et al., 2008. Domain implementation in software product lines using OSGi. Proceedings of the 7th International Conference on CompositionBased Software Systems, Feb. 25-29, IEEE Xplore Press, Madrid, Spain, pp: 72-81. DOI: $10.1109 /$ ICCBSS.2008.19

Andersen, N., K. Czarnecki, S. She and A. Wasowski, 2012. Efficient synthesis of feature models. Proceedings of the 16th International Software Product Line Conference, Sept. 02-07, ACM, Salvador, Brazil, pp: 106-115. DOI: $10.1145 / 2362536.2362553$ 
Apel, S., D. Batory, C. Kästner and G. Saake, 2013a Feature-Oriented Software Product Lines: Concepts and Implementation. 1st Edn., Springer, ISBN-10: 3662513005, pp: 332.

Apel, S., A.V. Rhein, P. Wendler, A. Groblinger and D. Beyer, 2013b. Strategies for product-line verification: Case studies and experiments. Proceedings of the 35th International Conference on Software Engineering, May 18-26, IEEE Xplore Press, San Francisco, CA, USA, pp: 482-491. DOI: 10.1109/ICSE.2013.6606594

Arrieta, A., G. Sagardui and L. Etxeberria, 2015. Test control algorithms for the validation of cyberphysical systems product lines. Proceedings of the 19th International Conference on Software Product Line, Jul. 20-24, ACM, Nashville, Tennessee, pp: 273-282. DOI: 10.1145/2791060.2791095

Arrieta, A., S. Wang, G. Sagardui and L. Etxeberria, 2016. Search-based test case selection of cyberphysical system product lines for simulation-based validation. Proceedings of the 20th International Systems and Software Product Line Conference, Sept. 16-23, ACM, Beijing, China, pp: 297-306. DOI: $10.1145 / 2934466.2946046$

Asadi, M., G. Groner, B. Mohabbati and D. Gasevic, 2016a. Goal-oriented modeling and verification of feature-oriented product lines. Software Syst. Model., 15: 257-279. DOI: 10.1007/s10270-014-0402-8

Asadi, M., S. Soltani, Gasevic, D. and M. Hatala, 2016b. The effects of visualization and interaction techniques on feature model configuration. Empirical Software Eng., 21: 1706-1743.

DOI: $10.1007 / \mathrm{s} 10664-014-9353-5$

Asadi, M., S. Soltani, D. Gasevic, M. Hatala and E. Bagheri, 2014. Toward automated feature model configuration with optimizing non-functional requirements. Inform. Software Technol., 56: 1144-1165. DOI: 10.1016/j.infsof.2014.03.005

Bagheri, E., F. Ensan and D. Gasevic, 2012a. Decision support for the software product line domain engineering lifecycle. Automated Software Eng., 19: 335-377. DOI: 10.1007/s10515-011-0099-7

Bagheri, E., F. Ensan and D. Gasevic, 2012b. Grammarbased test generation for software product line feature models. Proceedings of the Conference of the Center for Advanced Studies on Collaborative Research, Nov. 05-07, IBM Corp., Toronto, Ontario, Canada, pp: 87-101.

Bagheri, E. and D. Gasevic, 2011. Assessing the maintainability of software product line feature models using structural metrics. Software Quality J., 19: 579-612. DOI: 10.1007/s11219-010-9127-2

Barreiros, J. and A. Moreira, 2014. A cover-based approach for configuration repair. Proceedings of the 18th International Software Product Line Conference, Sept. 15-19, ACM, Florence, Italy, pp: 157-166. DOI: $10.1145 / 2648511.2648528$
Basili, V.R. and H.D. Rombach, 1988. The TAME project: Towards improvement-oriented software environments. IEEE Trans. Software Eng., 14: 758-773. DOI: 10.1109/32.6156

Becan, G., R. Behjati, A. Gotlieb and M. Acher, 2015. Synthesis of attributed feature models from product descriptions. Proceedings of the 19th International Conference on Software Product Line, Jul. 20-24, ACM, Nashville, Tennessee, pp: 1-10. DOI: $10.1145 / 2791060.2791068$

Ben-David, S., B. Sterin, J.M. Atlee and S. Beidu, 2015. Symbolic model checking of product-line requirements using sat-based methods. Proceedings of the IEEE/ACM 37th IEEE International Conference on Software Engineering, May 16-24, IEEE Xplore Press, Florence, Italy, pp: 189-199. DOI: $10.1109 /$ ICSE.2015.40

Bera, M.H.G., E. OliveiraJr and T.E. Colanzi, 2015. Evidence-based smarty support for variability identification and representation in component models. Proceedings of the 17th International Conference on Enterprise Information Systems, Apr. 27-30, Science and Technology Publications, Barcelona, Spain, pp: 295-302. DOI: 10.5220/0005366402950302

Bodden, E., T. Toledo, M. Ribeiro, C. Brabrand and P.

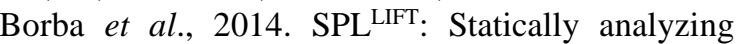
software product lines in minutes instead of years. Proceedings of the 34th ACM SIGPLAN Conference on Programming Language Design and Implementation, Jun. 16-19, ACM, Seattle, Washington, USA, pp: 355-364.

DOI: $10.1145 / 2491956.2491976$

Bonifacio, R., P. Borba, C. Ferraz and P. Accioly, 2017. Empirical assessment of two approaches for specifying software product line use case scenarios. Software Syst. Model., 16: 97-123. DOI: $10.1007 / \mathrm{s} 10270-015-0471-3$

Burdek, J., T. Kehrer, M. Lochau, D. Reuling and U. Kelter et al., 2016. Reasoning about productline evolution using complex feature model differences. Automated Software Eng., 23: 687-733. DOI: $10.1007 / \mathrm{s} 10515-015-0185-3$

Burdek, J., M. Lochau, S. Bauregger, A. Holzer and A. Von Rhein et al., 2015. Facilitating reuse in multigoal test-suite generation for software product lines. Proceedings of the International Conference on Fundamental Approaches to Software Engineering, Apr. 11-18, Springer, London, UK, pp: 84-99.

DOI: 10.1007/978-3-662-46675-9_6

Calvagna, A., A. Gargantini and P. Vavassori, 2013. Combinatorial testing for feature models using CitLab. Proceedings of the IEEE Sixth International Conference on Software Testing, Verification and Validation Workshops, IEEE Xplore Press, Luxembourg, pp: 338-347. DOI: $10.1109 /$ ICSTW.2013.45 
Cavalcanti, R.D.O., E.S.D. Almeida and S.R.L. Meira, 2011. Extending the RiPLE-DE process with quality attribute variability realization. Proceedings of the Federated Events on Component-Based Software Engineering and Software Architecture, Jun. 20-24, ACM, Boulder, Colorado, USA., pp: 159-164.

DOI: $10.1145 / 2000259.2000286$

Chiquitto, A.G., I.M.S. Gimenes and E. OliveiraJr, 2015. SyMPLES-CVL: A SysML and CVL based approach for product-line development of embedded systems. Proceedings of the 9th Brazilian Symposium on Components, Architectures and Reuse Software, Sept. 21-22, IEEE Xplore Press, Belo Horizonte, Brazil, pp: 21-30.

DOI: 10.1109/SBCARS.2015.13

Cirilo, E., I. Nunes, A. Garcia and C. Lucena, 2011. Configuration knowledge of software product lines: A comprehensibility study. Proceedings of the 2nd International Workshop on Variability and Composition, Mar. 21-21, ACM, Porto de Galinhas, Brazil, pp: 1-5. DOI: 10.1145/1961359.1961361

Clements, P. and L. Northrop, 2002. Software Product Lines: Practices and Patterns. 3rd Edn., AddisonWesley, Boston, ISBN-10: 0201703327, pp: 563.

Colanzi, T.E. and S.R. Vergilio, 2014a. A comparative analysis of two multi-objective evolutionary algorithms in product line architecture design optimization. Proceedings of the IEEE 26th International Conference on Tools with Artificial Intelligence, Nov. 10-12, IEEE Xplore Press, Limassol, Cyprus, pp: 681-688.

DOI: $10.1109 /$ ICTAI.2014.107

Colanzi, T.E. and S.R. Vergilio, 2014b. A feature-driven crossover operator for product line architecture design optimization. Proceedings of the IEEE 38th Annual Computer Software and Applications Conference, Jul. 21-25, IEEE Xplore Press, Vasteras, Sweden, pp: 43-52.

DOI: 10.1109/COMPSAC.2014.11

Colanzi, T.E. and S.R. Vergilio, 2016. A feature-driven crossover operator for multi-objective and evolutionary optimization of product line architectures. J. Syst. Software, 121: 126-143. DOI: $10.1016 /$ j.jss.2016.02.026

Conejero, J.M., E. Figueiredo, A. Garcia, J. Hernandez and E. Jurado, 2012. On the relationship of concern metrics and requirements maintainability. Inform. Software Technol., 54: 212-238. DOI: 10.1016/j.infsof.2011.09.003

Cordy, M., P. Heymans, A. Legay, P.Y. Schobbens and B. Dawagne et al., 2014. Counterexample guided abstraction refinement of product-line behavioural models. Proceedings of the 22nd ACM SIGSOFT International Symposium on Foundations of Software Engineering, Nov. 16-21, ACM, Hong Kong, China, pp: 190-201.

DOI: $10.1145 / 2635868.2635919$
Cordy, M., P.Y. Schobbens, P. Heymans and A. Legay, 2012. Behavioural modelling and verification of real-time software product lines. Proceedings of the 16th International Software Product Line Conference, Sept. 02-07, ACM, Salvador, Brazil, pp: 66-75. DOI: 10.1145/2362536.2362549

Cordy, M., P.Y. Schobbens, P. Heymans and A. Legay, 2013. Beyond boolean product-line model checking: Dealing with feature attributes and multi-features. Proceedings of the 35th International Conference on Software Engineering, May 18-26, IEEE Xplore Press, San Francisco, CA, USA, pp: 472-481. DOI: 10.1109/ICSE.2013.6606593

Cunha, R., T. Conte, E.S.D. Almeida and J.C. Maldonado, 2012. A set of inspection techniques on software product line models. SEKE.

Denger, C. and R. Kolb, 2006. Testing and inspecting reusable product line components: First empirical results. Proceedings of the International Symposium on Empirical Software Engineering, Sept. 21-22, ACM, Rio de Janeiro, Brazil, pp: 184-193. DOI: $10.1145 / 1159733.1159762$

Dermeval, D., T. Tenorio, I.I. Bittencourt, A. Silva and S. Isotani et al., 2015. Ontologybased feature modeling: An empirical study in changing scenarios. Expert Syst. Applic., 42: 4950-4964.

DOI: 10.1016/j.eswa.2015.02.020

Dieste, O., A. Grim, N. Juristo and H. Saxena, 2011. Quantitative determination of the relationship between internal validity and bias in software engineering experiments: Consequences for systematic literature reviews. Proceedings of the 5th International Symposium on Empirical Software Engineering and Measurement, Sept. 22-23, IEEE Xplore Press, Banff, AB, Canada, pp: 285-294. DOI: 10.1109/ESEM.2011.37

Dieste, O. and N. Juristo, 2013. Challenges of Evaluating the Quality of Software Engineering Experiments. In: Perspectives on the Future of Software Engineering, Münch, J. and K. Schmid (Eds.), Springer Berlin Heidelberg, pp: 159-177.

Duran-Limon, H.A., C.A. Garcia-Rios, F.E. CastilloBarrera and R. Capilla, 2015. An ontology-based product architecture derivation approach. IEEE Trans. Software Eng., 41: 1153-1168. DOI: 10.1109/TSE.2015.2449854

Elfaki, A.O., S.L. Fong, P. Vijayaprasad, M.G.M. Johar and M.S. Fadhil, 2014. Using a rule based method for detecting anomalies in software product line. Res. J. Applied Sci. Eng. Technol., 7: 275-81. DOI: $10.19026 /$ rjaset.7.251

Eyal-Salman, H. and A. Seriai, 2016. Toward recovering component-based software product line architecture from object-oriented product variants. Proceedings of the International Conference on Software Engineering and Knowledge Engineering, (EKE' 16), San Francisco, USA, pp: 1-7. 
Eyal-Salman, H., A.D. Seriai and C. Dony, 2013. Featureto-code traceability in legacy software variants. Proceedings of the 39th Euromicro Conference on Software Engineering and Advanced Applications, Sept. 4-6, IEEE Xplore Press, Santander, Spain, pp: 57-61. DOI: 10.1109/SEAA.2013.65

Eyal-Salman, H., A.D. Seriai and C. Dony, 2014. Feature location in a collection of product variants: Combining information retrieval and hierarchical clustering. Proceedings of the 26th International Conference on Software Engineering and Knowledge Engineering, (EKE’ 14), Vancouver, Canada, pp: 426-430.

Eyal-Salman, H., A.D. Seriai and C. Dony, 2015. Feature-level change impact analysis using formal concept analysis. Int. J. Software Eng. Knowl. Eng., 25: 69-92. DOI: 10.1142/S0218194015400045

Farias, K., A. Garcia and C. Lucena, 2014. Effects of stability on model composition effort: An exploratory study. Software Syst. Model., 13: 1473-1494.

DOI: $10.1007 / \mathrm{s} 10270-012-0308-2$

Federle, E.L., T.D.N. Ferreira, T.E. Colanzi and S.R. Vergilio, 2015. Optimizing software product line architectures with OPLA-tool. Proceedings of the 7th International Symposium on Search Based Software Engineering, Sept. 5-7, Bergamo, Italy, pp: 325-331. DOI: 10.1007/978-3-319-22183-0_30

Feigenspan, J., C. Kastner, S. Apel, J. Liebig and M. Schulze et al., 2013. Do background colors improve program comprehension in the\# ifdef hell? Empirical Software Eng., 18: 699-745.

DOI: $10.1007 / \mathrm{s} 10664-012-9208-\mathrm{x}$

Feigenspan, J., M. Schulze, M. Papendieck, C. Kastner and R. Dachselt et al., 2011. Using background colors to support program comprehension in software product lines. Proceedings of the 15th Annual Conference on Evaluation and Assessment in Software Engineering, Apr. 11-12, IEEE Xplore Press, Durham, UK, pp: 66-75.

DOI: 10.1049/ic.2011.0008

Feigenspan, J., M. Schulze, M. Papendieck, C. Kastner and R. Dachselt et al., 2012. Supporting program comprehension in large preprocessor-based software product lines. IET Software, 6: 488-501.

DOI: 10.1049/iet-sen.2011.0172

Fernandes, P., C. Werner and E. Teixeira, 2011. An approach for feature modeling of context-aware software product line. JUCS, 17: 807-829.

Fernandez-Amoros, D., R. Heradio, J.A. Cerrada and C. Cerrada, 2014. A scalable approach to exact model and commonality counting for extended feature models. IEEE Trans. Software Eng., 40: 895-910. DOI: $10.1109 /$ TSE.2014.2331073
Ferreira, F., P. Borba, G. Soares and R. Gheyi, 2012. Making software product line evolution safer. Proceedings of the 6th Brazilian Symposium on Software Components, Architectures and Reuse, Sept. 23-28, IEEE Xplore Press, Natal, Brazil, pp: 21-30. DOI: 10.1109/SBCARS.2012.18

Ferreira, F., R. Gheyi, P. Borba and G. Soares, 2014. A toolset for checking SPL refinements. JUCS, 20: 587-614.

Fleiss, J.L., B. Levin and M.C. Paik, 2003. Statistical Methods for Rates and Proportions. 1st Edn., Wiley Series in Probability and Statistics, ISBN-13: 978-0-471-52629-2, pp: 800.

Galindo, J.A., D. Dhungana, R. Rabiser, D. Benavides, G. Botterweck and P. Grunbacher, 2015. Supporting distributed product configuration by integrating heterogeneous variability modeling approaches. Inform. Software Technol., 62: 78-100.

DOI: 10.1016/j.infsof.2015.02.002

Gamez, N. and L. Fuentes, 2013. Architectural evolution of famiware using cardinality-based feature models. Inform. Software Technol., 55: 563-580. DOI: 10.1016/j.infsof.2012.06.012

Gheyi, R., T. Massoni and P. Borba, 2011. Automatically checking feature model refactorings. JUCS, 17: 684-711.

Ghezzi, C. and A.M. Sharifloo, 2013. Model-based verification of quantitative non-functional properties for software product lines. Inform. Software Technol., 55: 508-524. DOI: 10.1016/j.infsof.2012.07.017

Goncalves, T.L., I.M.D.S. Gimenes, M. Fantinato, G.H. Travassos and M.B.F.D. Toledo, 2011. Experimental studies of e-contract establishment in the pl4bpm context. Int. J. Web Eng. Technol., 6: 243-265. DOI: 10.1504/IJWET.2011.040724

Gonzalez-Huerta, J., E. Insfran and S. Abrahao, 2013. Defining and validating a multimodel approach for product architecture derivation and improvement. Proceedings of the 16th International Conference on Model-Driven Engineering Languages and Systems, Sept. 29-Oct. 04, Springer, USA, pp: 388-404. DOI: 10.1007/978-3-642-41533-3_24

Guana, V. and D. Correal, 2013. Improving software product line configuration: A quality attributedriven approach. Inform. Software Technol., 55: 541-562. DOI: 10.1016/j.infsof.2012.09.007

Guo, J., Y. Wang, P. Trinidad and D. Benavides, 2012. Consistency maintenance for evolving feature models. Expert Syst. Applic., 39: 4987-4998. DOI: 10.1016/j.eswa.2011.10.014

Guo, J., J. White, G. Wang, J. Li and Y. Wang, 2011. A genetic algorithm for optimized feature selection with resource constraints in software product lines. J. Syst. Software, 84: 2208-2221. DOI: 10.1016/j.jss.2011.06.026 
Halmans, G. and K. Pohl, 2003. Communicating the variability of a software-product family to customers. Software Syst. Model., 2: 15-36.

DOI: $10.1007 / \mathrm{s} 10270-003-0019-9$

Hartmann, H. and T. Trew, 2008. Using feature diagrams with context variability to model multiple product lines for software supply chains. Proceedings of the 12th International Software Product Line Conference, Sept. 8-12, IEEE Xplore Press, Limerick, Ireland, pp: 12-21. DOI: 10.1109/SPLC.2008.15

Hashim, N.L., H.W. Schmidt and S. Ramakrishnan, 2005. Test order for class-based integration testing of java applications. Proceedings of the 5th International Conference on Quality Software, Sept. 19-20, IEEE Xplore Press, Melbourne, Victoria, Australia, pp: 11-18. DOI: 10.1109/QSIC.2005.64

Henard, C., M. Papadakis, M. Harman and Y. Le Traon, 2015. Combining multi-objective search and constraint solving for configuring large software product lines. Proceedings of the IEEE/ACM 37th IEEE International Conference on Software Engineering, May 16-24, IEEE Xplore Press, Florence, Italy, pp: 517-528. DOI: 10.1109/ICSE.2015.69

Henard, C., M. Papadakis, G. Perrouin, J. Klein and P. Heymans et al., 2014. Bypassing the combinatorial explosion: Using similarity to generate and prioritize t-wise test configurations for software product lines. IEEE Trans. Software Eng., 40: 650-670. DOI: 10.1109/TSE.2014.2327020

Henard, C., M. Papadakis, G. Perrouin, J. Klein and Y. Le Traon, 2013a. Assessing software product line testing via model-based mutation: An application to similarity testing. Proceedings of the IEEE Sixth International Conference on Software Testing, Verification and Validation Workshops, Mar. 18-22, IEEE Xplore Press, Luxembourg, pp: 188-197. DOI: 10.1109/ICSTW.2013.30

Henard, C., M. Papadakis, G. Perrouin, J. Klein and Y.L. Traon, 2013b. Multi-objective test generation for software product lines. Proceedings of the 17th International Software Product Line Conference, Aug. 26-30, ACM, Tokyo, Japan, pp: 62-71. DOI: $10.1145 / 2491627.2491635$

Heradio-Gil, R., D. Fernandez-Amoros, J.A. Cerrada and C. Cerrada, 2011. Supporting commonality-based analysis of software product lines. IET Software, 5: 496-509. DOI: 10.1049/iet-sen.2010.0022

Hervieu, A., B. Baudry and A. Gotlieb, 2011. PACOGEN: Automatic generation of pairwise test configurations from feature models. Proceedings of the IEEE 22nd International Symposium on Software Reliability Engineering, Nov. 29-Dec. 2, IEEE Xplore Press, Hiroshima, Japan, pp: 120-129. DOI: 10.1109/ISSRE.2011.31
Hervieu, A., D. Marijan, A. Gotlieb and B. Baudry, 2016. Practical minimization of pairwise-covering test configurations using constraint programming. Inform. Software Technol., 71: 129-146. DOI: $10.1016 /$ j.infsof.2015.11.007

Hierons, R.M., M. Li, X. Liu, S. Segura and W. Zheng, 2016. Sip: Optimal product selection from feature models using many-objective evolutionary optimization. Trans. Software Eng. Methodol., 25: 1-17. DOI: $10.1145 / 2897760$

Ianzen, A., R.M. Fontana, M.A. Paludo, A. Malucelli and S. Reinehr, 2015. Scoping automation in software product lines. Proceedings of the International Conference on Enterprise Information Systems, (EIS’ 15), Barcelona, Spain, pp: 82-91.

Jaksic, A., R.B. France, P. Collet and S. Ghosh, 2014. Evaluating the usability of a visual feature modeling notation. Proceedings of the International Conference on Software Language Engineering, (SLE' 14), Springer, Cham, pp: 122-140.

Jedlitschka, A., M. Ciolkowski and D. Pfahl, 2008. Reporting Experiments in Software Engineering. In: Guide to Advanced Empirical Software Engineering, Shull, F., J. Singer and D.I.K. Sjøberg (Eds.), Springer, London, pp: 201-228.

Jirapanthong, W., 2008. An approach to software artefact specification for supporting product line systems. Software Engineering Research and Practice, pp: 548-554.

Jirapanthong, W. and A. Zisman, 2009. XTraQue: Traceability for product line systems. Software Syst. Model., 8: 117-144. DOI: 10.1007/s10270-007-0066-8

Johansen, M.F., Ø. Haugen and F. Fleurey, 2012. An algorithm for generating t-wise covering arrays from large feature models. Proceedings of the 16th International Software Product Line Conference, Sept. 02-07, ACM, Salvador, Brazil, pp: 46-55. DOI: $10.1145 / 2362536.2362547$

John, I., 2006. Capturing Product Line Information from Legacy User Documentation. In: Software Product Lines: Research Issues in Engineering and Management, Käköla, T. and J.C. Duenas (Eds.), Springer, pp: 127-159.

John, I. and A. Silva, 2011. Evaluating variability instantiation strategies for product lines. Proceedings of the 5th Workshop on Variability Modeling of Software-Intensive Systems, Jan. 27-29, ACM, Namur, Belgium, pp: 105-113.

DOI: $10.1145 / 1944892.1944905$

Kamischke, J., M. Lochau and H. Baller, 2012. Conditioned model slicing of feature-annotated state machines. Proceedings of the 4th International Workshop on Feature-Oriented Software Development, Sept. 24-25, ACM, Dresden, Germany, pp: 9-16. DOI: 10.1145/2377816.2377818 
Kampenes, V., 2007. Quality of design, analysis and reporting of software engineering experiments: A systematic review. PhD Thesis, University of Oslo.

Kim, C.H.P., D. Marinov, S. Khurshid, D. Batory and S. Souto et al., 2013. SPLat: Lightweight dynamic analysis for reducing combinatorics in testing configurable systems. Proceedings of the 9th Joint Meeting on Foundations of Software Engineering, Aug. 18-26, ACM, Saint Petersburg, Russia, pp: 257-267. DOI: 10.1145/2491411.2491459

Kitchenham, B. and S. Charters, 2007. Guidelines for performing systematic literature reviews in software engineering. Technical Report EBSE 2007-001, Keele University and Durham University Joint Report.

Kitchenham, B., D.I.K. Sjøberg, O.P. Brereton, D. Budgen and T. Dyba et al., 2010. Can we evaluate the quality of software engineering experiments? Proceedings of the ACM-IEEE International Symposium on Empirical Software Engineering and Measurement, Sept. 16-17, ACM, Bolzano-Bozen, Italy, pp: 1-8. DOI: $10.1145 / 1852786.1852789$

Kitchenham, B.A., D. Budgen and P. Brereton, 2015. Evidence-Based Software Engineering and Systematic Reviews. 1st Edn., CRC Press, ISBN-10: 1482228661, pp: 299.

Kitchenham, B.A., S.L. Pfleeger, L.M. Pickard, P.W. Jones and D.C. Hoaglin et al., 2002. Preliminary guidelines for empirical research in software engineering. IEEE Trans. Software Eng., 28: 721-734.

DOI: 10.1109/TSE.2002.1027796

Kitchenham, B.A., D.I.K. Sjøberg, T. Dyba, D. Pfahl and P. Brereton et al., 2012. Three empirical studies on the agreement of reviewers about the quality of software engineering experiments. Inform. Software Technol., 54: 804-819.

DOI: $10.1016 /$ j.infsof.2011.11.008

Kolesnikov, S., A. von Rhein, C. Hunsen and S. Apel, 2014. A comparison of product-based, feature based and family-based type checking. Proceedings of the International Conference on Generative Programming: Concepts and Experiences, 49: 115-124.

DOI: $10.1145 / 2637365.2517213$

Lamine, S.B.A.B., L.L. Jilani and H.H.B. Ghezala, 2005. A software cost estimation model for a product line engineering approach: Supporting tool and UML modeling. Proceedings of the 3rd ACIS International Conference on Software Engineering Research, Management and Applications, Aug. 1113, IEEE Xplore Press, Mount Pleasant, MI, USA, pp: 383-390. DOI: 10.1109/SERA.2005.16

Lee, S.B., J.W. Kim, C.Y. Song and D.K. Baik, 2007. An approach to analyzing commonality and variability of features using ontology in a software product line engineering. Proceedings of the 5th ACIS International Conference on Software Engineering Research, Management and Applications, Aug. 20-22, IEEE Xplore Press, Busan, South Korea, pp: 727-734. DOI: 10.1109/SERA.2007.41
Lengauer, P., V. Bitto, F. Angerer, P. Grunbacher and H. Mossenbock, 2014. Where has all my memory gone?: Determining memory characteristics of product variants using virtual-machine-level monitoring. Proceedings of the 8th International Workshop on Variability Modelling of Software-Intensive Systems, Jan. 22-24, ACM, Sophia Antipolis, France, pp: 13-13. DOI: $10.1145 / 2556624.2556628$

Lian, X. and L. Zhang, 2015. Optimized feature selection towards functional and non-functional requirements in software product lines. Proceedings of the IEEE 22nd International Conference on Software Analysis, Evolution and Reengineering, Mar. 2-6, IEEE Xplore Press, Montreal, QC, Canada, pp: 191-200.

DOI: 10.1109/SANER.2015.7081829

Neto, L., C. Rodrigues, E.S.D. Almeida and S.R.D.L. Meira, 2012. A software product lines system test case tool and its initial evaluation. Proceedings of the IEEE 13th International Conference on Information Reuse and Integration, Aug. 8-10, IEEE Xplore Press, Las Vegas, NV, USA, pp: 25-32. DOI: 10.1109/IRI.2012.6302986

Neto, L., C. Rodrigues, I.D.C. Machado, V.C. Garcia and E.S.D. Almeida, 2013. Analyzing the effectiveness of a system testing tool for software product line engineering. Proceedings of the 25th International Conference on Software Engineering and Knowledge Engineering, (EKE' 03), At Boston, pp: 584-588.

Linden, F.J.V.D., K. Schmid and E. Rommes, 2007. Software Product Lines in Action: The Best Industrial Practice in Product Line Engineering. 1st Edn., Springer, New York, ISBN-10: 3540714375 , pp: 333.

Lity, S., M. Lochau, I. Schaefer and U. Goltz, 2012. Delta-oriented model-based SPL regression testing. Proceedings of the 3rd International Workshop on Product LinE Approaches in Software Engineering, Jun. 4-4, IEEE Xplore Press, Zurich, Switzerland, pp: 53-56. DOI: 10.1109/PLEASE.2012.6229772

LiZhang, X.L., 2014. An evolutionary methodology for optimized feature selection in software product lines. Proceedings of the International Conference on Software Engineering and Knowledge Engineering, (EKE' 14).

Lochau, M., S. Mennicke, H. Baller and L. Ribbeck, 2016. Incremental model checking of delta-oriented software product lines. J. Logical Algebraic Meth. Programm., 85: 245-267.

DOI: 10.1016/j.jlamp.2015.09.004

Lopez-Herrejon, R.E., L. Linsbauer, J.A. Galindo, J.A. Parejo and D. Benavides et al., 2015. An assessment of search-based techniques for reverse engineering feature models. J. Syst. Software, 103: 353-369. DOI: 10.1016/j.jss.2014.10.037 
Machado, I.C., E.S. Almeida, G.S.S. Gomes, P.A.M. Silveira Neto and R.L. Novais et al., 2012. A preliminary study on the effects of working with a testing process in software product line projects. Proceedings of the Workshop Latinoamericano de Ingenierıa de Software Experimental, (ISE' 12).

Machado, I.D.C., P.A.D.M. Silveira Neto, E.S.D. Almeida and S.R.D.L. Meira, 2011. RIPLE-TE: A process for testing software product lines. SEKE.

Marcolino, A., E. OliveiraJr and I.M.D.S. Gimenes, 2014a. Variability identification and representation in software product line UML sequence diagrams: Proposal and empirical study. Proceedings of the Brazilian Symposium on Software Engineering, Sept. 28-Oct. 3, IEEE Xplore Press, Maceio, Brazil, pp: 141-150. DOI: 10.1109/SBES.2014.11

Marcolino, A., E. OliveiraJr, I.M.D.S. Gimenes and E.F. Barbosa, 2014b. Empirically based evolution of a variability management approach at UML class level. Proceedings of the IEEE 38th Annual Computer Software and Applications Conference, Jul. 21-25, IEEE Xplore Press, Vasteras, Sweden, pp: 354-363. DOI: 10.1109/COMPSAC.2014.58

Marcolino, A., E. OliveiraJr, I.M.D.S. Gimenes and T.U. Conte, 2013a. Towards validating complexity-based metrics for software product line architectures. Proceedings of the $7 \mathrm{th}$ Brazilian Symposium on Software Components, Architectures and Reuse, Sept. 29-Oct. 4, IEEE Xplore Press, Brasilia, Brazil, pp: 69-79.

DOI: $10.1109 /$ SBCARS.2013.18

Marcolino, A., E. OliveiraJr, I.M.D.S. Gimenes and J.C. Maldonado, 2013b. Towards the effectiveness of a variability management approach at use case level. Proceedings of the International Conference on Software Engineering and Knowledge Engineering, (EKE' 13), At Boston, pp: 214-219.

Mariani, T., T.E. Colanzi and S.R. Vergilio, 2016. Preserving architectural styles in the search based design of software product line architectures. J. Syst. Software, 115: 157-173.

DOI: $10.1016 /$ j.jss.2016.01.039

Mariani, T., S.R. Vergilio and T.E. Colanzi, 2015. Search based design of layered product line architectures. Proceedings of the IEEE 39th Annual Computer Software and Applications Conference, Jul. 1-5, IEEE Xplore Press, Taichung, Taiwan, pp: 270-275. DOI: 10.1109/COMPSAC.2015.30

Marijan, D., A. Gotlieb, S. Sen and A. Hervieu, 2013. Practical pairwise testing for software product lines. Proceedings of the 17th International Software Product Line Conference, Aug. 26-30, ACM, Tokyo, Japan, pp: 227-235. DOI: 10.1145/2491627.2491646
Medeiros, A.L., E. Cavalcante, T. Batista and E. Silva, 2015. ArchSPL-MDD: An ADL-based model-driven strategy for automatic variability management. Proceedings of the 9th Brazilian Symposium on Components, Architectures and Reuse Software, Sept. 21-22, IEEE Xplore Press, Belo Horizonte, Brazil, pp: 120-129. DOI: 10.1109/SBCARS.2015.23

Medeiros, F.M., E.S.D. Almeida and S.R.D.L. Meira, 2010a. Designing a set of service-oriented systems as a software product line. Proceedings of the 4th Brazilian Symposium on Software Components, Architectures and Reuse, Sept. 27-29, IEEE Xplore Press, Bahia, Brazil, pp: 70-79. DOI: 10.1109/SBCARS.2010.17

Medeiros, F.M., E.S.D. Almeida and S.R.L. Meira, 2010b. SOPLE-DE: An approach to design serviceoriented product line architectures. Proceedings of the 14th International Conference on Software Product Lines: Going Beyond, Sept. 13-17, Springer, Jeju Island, South Korea, pp: 456-460. DOI: $10.1007 / 978-3-642-15579-6 \_36$

Medvidovic, N. and R.N. Taylor, 2010. Software architecture: foundations, theory and practice. Proceedings of the 32nd ACM/IEEE International Conference on Software Engineering, May 01-08, ACM, Cape Town, South Africa, pp: 471-472. DOI: $10.1145 / 1810295.1810435$

Mefteh, M., N. Bouassida and H. Ben-Abdallah, 2015. Implementation and evaluation of an approach for extracting feature models from documented UML use case diagrams. Proceedings of the Symposium on Applied Computing, Apr.13-17, ACM, Salamanca, Spain, pp: 1602-1609.

DOI: $10.1145 / 2695664.2695907$

Mello, R.M.D., E. Nogueira, M. Schots, C.M.L. Werner and G.H. Travassos, 2014. Verification of software product line artefacts: A checklist to support feature model inspections. JUCS, 20: 720-745.

Michalik, B., D. Weyns, N. Boucke and A. Helleboogh, 2011a. Supporting online updates of software product lines: A controlled experiment. Empirical Software Engineering and Measurement, pp: 187-196.

Michalik, B., D. Weyns, N. Boucke and A. Helleboogh, 2011b. Supporting online updates of software product lines: A controlled experiment. Proceedings of the International Symposium on Empirical Software Engineering and Measurement, Sept. 22-23, IEEE Xplore Press, Banff, AB, Canada, pp: 187-196. DOI: 10.1109/ESEM.2011.27

Millo, J.V. and S. Ramesh, 2012. Relating requirement and design variabilities. Proceedings of the 19th AsiaPacific Software Engineering Conference, Dec. 4-7, IEEE Xplore Press, Hong Kong, China, pp: 35-42. DOI: 10.1109/APSEC.2012.67 
Murashkin, A., M. Antkiewicz, D. Rayside and K. Czarnecki, 2013a. Visualization and exploration of optimal variants in product line engineering. Proceedings of the 17th International Software Product Line Conference, Aug. 26-30, ACM, Tokyo, Japan, pp: 111-115. DOI: 10.1145/2491627.2491647

Murashkin, A., M. Antkiewicz, D. Rayside and K. Czarnecki, 2013b. Visualization and exploration of optimal variants in product line engineering. Proceedings of the 17th International Software Product Line Conference, Aug. 26-30, ACM, Tokyo, Japan, pp: 111-115. DOI: 10.1145/2491627.2491647

Neiva, D.F.S., E.S.D. Almeida and S.R.D.L. Meira, 2009. An experimental study on requirements engineering for software product lines. Proceedings of the 35th Euromicro Conference on Software Engineering and Advanced Applications, Aug. 27-29, IEEE Xplore Press, Patras, Greece, pp: 251-254. DOI: $10.1109 /$ SEAA.2009.32

Nie, K., L. Zhang and Z. Geng, 2012. Product line variability modeling based on model difference and merge. Proceedings of the IEEE 36th Annual Computer Software and Applications Conference Workshops, Jul. 16-20, IEEE Xplore Press, Izmir, Turkey, pp: 509-513. DOI: 10.1109/COMPSACW.2012.95

Niu, N., J. Savolainen, Z. Niu, M. Jin and J.R.C. Cheng, 2014. A systems approach to product line requirements reuse. IEEE Syst. J., 8: 827-836. DOI: 10.1109/JSYST.2013.2260092

Nunes, C., U. Kulesza, C. Sant'Anna, I. Nunes and A.F. Garcia et al., 2009. Assessment of the design modularity and stability of multi-agent system product lines. JUCS, 15: 2254-2283.

Olaechea, R., D. Rayside, J. Guo and K. Czarnecki, 2014. Comparison of exact and approximate multi-objective optimization for software product lines. Proceedings of the 18th International Software Product Line Conference, Sept. 15-19, ACM, Florence, Italy, pp: 92-101. DOI: $10.1145 / 2648511.2648521$

Oliveira, D.R.F., B.L.D. Bezerra, E.L.S.X. Freitas and A.M.A. Maciel, 2015. Adoption of software product line to a voice user interface environment. Proceedings of the International Conference on Software Engineering and Knowledge Engineering, Proceedings of the International Conference on Software Engineering and Knowledge Engineering, (EKE’ 15).

Oliveira, R.P.D. and E.S.D. Almeida, 2015. Requirements evolution in software product lines: An empirical study. Proceedings of the 9th Brazilian Symposium on Components, Architectures and Reuse Software, Sept. 21-22, IEEE Xplore Press, Belo Horizonte, Brazil, pp: 1-10. DOI: $10.1109 /$ SBCARS.2015.11
OliveiraJr, E., I.M.D.S. Gimenes and J.C. Maldonado, 2012. Empirical validation of variability-based complexity metrics for software product line architecture. SEKE.

OliveiraJr, E., J.C. Maldonado and I.M.D.S. Gimenes, 2010. Empirical validation of complexity and extensibility metrics for software product line architectures. Proceedings of the 4th Brazilian Symposium on Software Components, Architectures and Reuse, Sept. 27-29, IEEE Xplore Press, Bahia, Brazil, pp: 31-40. DOI: 10.1109/SBCARS.2010.13

Pascual, G.G., R.E. Lopez-Herrejon, M. Pinto, L. Fuentes and A. Egyed, 2015. Applying multiobjective evolutionary algorithms to dynamic software product lines for reconfiguring mobile applications. J. Syst. Software, 103: 392-411.

DOI: $10.1016 /$ j.jss.2014.12.041

Patel, S., P. Gupta and V. Shah, 2013a. Combinatorial interaction testing with multi-perspective feature models. Proceedings of the IEEE 6th International Conference on Software Testing, Verification and Validation Workshops, Mar. 18-22, IEEE Xplore Press, Luxembourg, pp: 321-330.

DOI: 10.1109/ICSTW.2013.43

Patel, S., P. Gupta and V. Shah, 2013b. Feature interaction testing of variability intensive systems. Proceedings of the 4th International Workshop on Product LinE Approaches in Software Engineering, May 20-20, IEEE Xplore Press, San Francisco, CA, USA, pp: 53-56.

DOI: 10.1109/PLEASE.2013.6608666

Petersen, K., S. Vakkalanka and L. Kuzniarz, 2015. Guidelines for conducting systematic mapping studies in software engineering: An update. Inform. Software Technol., 64: 1-18. DOI: $10.1016 /$ j.infsof.2015.03.007

Pohl, K., G. Bockle and F.J.V.D. Linden, 2005. Software Product Line Engineering: Foundations, Principles and Techniques. 1st Edn., Springer, New York, ISBN-10: 3540243720, pp: 467.

Pohl, R., K. Lauenroth and K. Pohl, 2011. A performance comparison of contemporary algorithmic approaches for automated analysis operations on feature models. Proceedings of the 26th IEEE/ACM International Conference on Automated Software Engineering, Nov. 6-10, IEEE Xplore Press, Lawrence, KS, USA, pp: 313-322. DOI: 10.1109/ASE.2011.6100068

Pohl, R., V. Stricker and K. Pohl, 2013. Measuring the structural complexity of feature models. Proceedings of the 28th IEEE/ACM International Conference on Automated Software Engineering, Nov. 11-15, IEEE Xplore Press, Silicon Valley, CA, USA, pp: 454-464. DOI: 10.1109/ASE.2013.6693103 
R Core Team, 2014. R: A language and environment for statistical computing. R Foundation for Statistical Computing, Vienna, Austria.

Rahmat, A., S. Kassim, M.H. Selamat and S. Hassan, 2016. Actor in multi product line. Proceedings of the 10th International Conference on Ubiquitous Information Management and Communication, Jan. 04-06, ACM, Danang, Viet Nam, pp: 61-61. DOI: $10.1145 / 2857546.2857608$

Reinhartz-Berger, I., K. Figl and Ø. Haugen, 2014a. Comprehending feature models expressed in CVL. Proceedings of the 17th International Conference on Model Driven Engineering Languages and Systems, Sept. 28-Oct. 3, Valencia, Spain, pp: 501-517. DOI: $10.1007 / 978-3-319-11653-2 \_31$

Reinhartz-Berger, I. and A. Sturm, 2014 b. Comprehensibility of UML-based software product line specifications. Empirical Software Eng., 19: 678-713. DOI: 10.1007/s10664-012-9234-8

Reinhartz-Berger, I. and A. Tsoury, 2011. Experimenting with the comprehension of feature-oriented and UMLbased core assets. Proceedings of the International Workshop on Business Process Modeling, Development and Support, (MDS' 11), Springer, pp: 468-482. DOI: 10.1007/978-3-642-21759-3 34

Reuling, D., J. Burdek, S. Rotarmel, M. Lochau and U. Kelter, 2015. Fault-based product-line testing: Effective sample generation based on feature-diagram mutation. Proceedings of the 19th International Conference on Software Product Line, Jul. 20-24, ACM, Nashville, Tennessee, pp: 131-140.

DOI: $10.1145 / 2791060.2791074$

Ribeiro, M., P. Borba and C. Kastner, 2014. Feature maintenance with emergent interfaces. Proceedings of the 36th International Conference on Software Engineering, May 31-Jun. 07, ACM, Hyderabad, India, pp: 989-1000.

DOI: $10.1145 / 2568225.2568289$

Rodrigues, G.N., V. Alves, V. Nunes, A. Lanna and M. Cordy et al., 2015. Modeling and verification for probabilistic properties in software product lines. Proceedings of the IEEE 16th International Symposium on High Assurance Systems Engineering, Jan. 8-10, IEEE Xplore Press, Daytona Beach Shores, FL, USA, pp: 173-180. DOI: 10.1109/HASE.2015.34

Rodrigues, I.P., A.P.T. Bacelo, M.S. Silveira, M.D.B. Campos and E.M. Rodrigues, 2016. Evaluating the representation of user interface elements in feature models: An empirical study. SEKE.

Romanovsky, K., D. Koznov and L. Minchin, 2011. Refactoring the documentation of software product lines. Proceedings of the 3rd IFIP TC 2 Central and East European Conference on Software Engineering Techniques, Oct. 13-15, Springer, Brno, Czech Republic, pp: 158-170.

DOI: $10.1007 / 978-3-642-22386-0 \_12$
Saeed, M., F. Saleh, S. Al-Insaif and M. El-Attar, 2016. Empirical validating the cognitive effectiveness of a new feature diagrams visual syntax. Inform. Software Technol., 71: 1-26. DOI: 10.1016/j.infsof.2015.10.012

Santos, A.R., I.D.C. Machado and E.S.D. Almeida, 2016. RiPLE-Hc: Javascript systems meets SPL composition. Proceedings of the 20th International Systems and Software Product Line Conference, Sept. 16-23, ACM, Beijing, China, pp: 154-163. DOI: $10.1145 / 2934466.2934486$

Santos, I.D.S., R.M.D.C. Andrade and P.D.A.D. Santos Neto, 2013. A use case textual description for context aware SPL based on a controlled experiment. CaiSE Forum.

Santos, W.B., E.S.D. Almeida and S.R.D.L. Meira, 2012. TIRT: A traceability information retrieval tool for software product lines projects. Proceedings of the 38th Euromicro Conference on Software Engineering and Advanced Applications, Sept. 5-8, IEEE Xplore Press, Cesme, Izmir, Turkey, pp: 93-100. DOI: 10.1109/SEAA.2012.40

Santos Neto, P.D.A., R. Britto, R.D.A.L. Rabelo, J.J.D.A. Cruz and W.A.L. Lira, 2016. A hybrid approach to suggest software product line portfolios. Applied Soft Comput., 49: 1243-1255.

DOI: $10.1016 /$ j.asoc.2016.08.024

Sayyad, A.S., T. Menzies and H. Ammar, 2013. On the value of user preferences in search-based software engineering: A case study in software product lines. Proceedings of the 35 th International Conference on Software Engineering, May 18-26, IEEE Xplore Press, San Francisco, CA, USA, pp: 492-501. DOI: 10.1109/ICSE.2013.6606595

Schroter, R., N. Siegmund, T. Thum and G. Saake, 2014. Feature-context interfaces: Tailored programming interfaces for software product lines. Proceedings of the 18th International Software Product Line Conference, Sept. 15-19, ACM, Florence, Italy, pp: 102-111. DOI: $10.1145 / 2648511.2648522$

Segura, S., D. Benavides and A. Ruiz-Cortes, 2011. Functional testing of feature model analysis tools: A test suite. IET Software, 5: 70-82.

DOI: 10.1049/iet-sen.2009.0096

Segura, S., J.A. Parejo, R.M. Hierons, D. Benavides and A. Ruiz-Cortes, 2014. Automated generation of computationally hard feature models using evolutionary algorithms. Expert Syst. Applic., 41: 3975-3992. DOI: 10.1016/j.eswa.2013.12.028

Shatnawi, A., A. Seriai and H.A. Sahraoui, 2015. Recovering architectural variability of a family of product variants. Proceedings of the 14th International Conference on Software Reuse, Jan. 46, Springer, Miami, FL, USA, pp: 17-33. DOI: $10.1007 / 978-3-319-14130-5 \_2$

Shi, R., J. Guo and Y. Wang, 2010. A preliminary experimental study on optimal feature selection for product derivation using knapsack approximation. Progress Inform. Comput., 1: 665-669. 
Siegmund, N., M. RosenmuLler, C. KaStner, P.G. Giarrusso and S. Apel et al., 2013. Scalable prediction of non-functional properties in software product lines: Footprint and memory consumption. Inform. Software Technol., 55: 491-507.

DOI: 10.1016/j.infsof.2012.07.020

Silveira Neto, P.A.D.M., I.D.C. Machado, Y.C. Cavalcanti, E.S.D. Almeida and V.C. Garcia et al., 2010. A regression testing approach for software product lines architectures. Proceedings of the 4th Brazilian Symposium on Software Components, Architectures and Reuse, Software Components, Architectures and Reuse, Sept. 27-29, IEEE Xplore Press, Bahia, Brazil, pp: 41-50. DOI: 10.1109/SBCARS.2010.14

Silveira Neto, P.A.D.M., I.D.C. Machado, Y.C. Cavalcanti, E.S.D. Almeida and V.C. Garcia et al., 2012. An experimental study to evaluate a SPL architecture regression testing approach. Proceedings of the IEEE 13th International Conference on Information Reuse and Integration, Aug. 8-10, IEEE Xplore Press, Las Vegas, NV, USA, pp: 608-615. DOI: 10.1109/IRI.2012.6303065

Sinnema, M. and S. Deelstra, 2008. Industrial validation of covamof. J. Syst. Software, 81: 584-600.

DOI: $10.1016 /$ j.jss.2007.06.002

Sjoberg, D.I.K., T. Dyba and M. Jorgensen, 2007. The future of empirical methods in software engineering research. Proceedings of the Future of Software Engineering, May 23-25, IEEE Xplore Press, Minneapolis, MN, USA, pp: 358-378. DOI: $10.1109 /$ FOSE.2007.30

Soltani, S., M. Asadi, D. Gasevic, M. Hatala and E. Bagheri, 2012. Automated planning for feature model configuration based on functional and nonfunctional requirements. Proceedings of the 16th International Software Product Line Conference, Sept. 02-07, ACM, Salvador, Brazil, pp: 56-65. DOI: $10.1145 / 2362536.2362548$

Sousa, G., W. Rudametkin and L. Duchien, 2016. Extending feature models with relative cardinalities. Proceedings of the 20th International Systems and Software Product Line Conference, Sept. 16-23, ACM, Beijing, China, pp: 79-88.

DOI: $10.1145 / 2934466.2934475$

Souto, S., D. Gopinath, M. d'Amorim, D. Marinov and S. Khurshid et al., 2015. Faster bug detection for software product lines with incomplete feature models. Proceedings of the 19th International Conference on Software Product Line, Jul. 20-24, ACM, Nashville, Tennessee, pp: 151-160.

DOI: $10.1145 / 2791060.2791093$

Souza, I.S., R.M.D. Mello, E.S.D. Almeida, C.M.L. Werner and G.H. Travassos, 2016a. Experimental evaluation of FMCheck: A replication study. Proceedings of the 15th Brazilian Symposium on Software Quality, (SSQ' 16), At Maceió, pp: 121-135.
Souza, M.L.D.J., A.R. Santos, I.D.C. Machado, E.S.D. Almeida and G.S.D.S. Gomes, 2016b. Evaluating variability modeling techniques for dynamic software product lines: A controlled experiment. Proceedings of the 10th Brazilian Symposium on Software Components, Architectures and Reuse, Sept. 19-20, IEEE Xplore Press, Maringa, Brazil, pp: 1-10. DOI: 10.1109/SBCARS.2016.15

Stein, J., I. Nunes and E. Cirilo, 2014. Preference-based feature model configuration with multiple stakeholders. Proceedings of the 18th International Software Product Line Conference, Sept. 15-19, ACM, Florence, Italy, pp: 132-141. DOI: $10.1145 / 2648511.2648525$

Stricker, V., A. Metzger and K. Pohl, 2010. Avoiding redundant testing in application engineering. Proceedings of the International Conference on Software Product Lines, (SPL' 10), Springer, Berlin, pp: 226-240. DOI: 10.1007/978-3-642-15579-6_16

Tan, L., Y. Lin, H. Ye and G. Zhang, 2013. Improving product configuration in software product line engineering. Proceedings of the 36th Australasian Computer Science Conference, Jan. 29-Feb. 01, Australian Computer Society, Inc., pp: 125-133. https://dl.acm.org/citation.cfm?id=2525415

Thum, T., D. Batory and C. Kastner, 2009. Reasoning about edits to feature models. Proceedings of the IEEE 31st International Conference on Software Engineering, May 16-24, IEEE Xplore Press, Vancouver, BC, Canada, pp: 254-264. DOI: 10.1109/ICSE.2009.5070526

Thum, T., J. Meinicke, F. Benduhn, M. Hentschel and A. von Rhein et al., 2014. Potential synergies of theorem proving and model checking for software product lines. Proceedings of the 18th International Software Product Line Conference, Sept. 15-19, ACM, Florence, Italy, pp: 177-186. DOI: $10.1145 / 2648511.2648530$

Thum, T., M. Ribeiro, R. Schroter, J. Siegmund and F. Dalton, 2016. Product-line maintenance with emergent contract interfaces. Proceedings of the 20th International Systems and Software Product Line Conference, Sept. 16-23, ACM, Beijing, China, pp: 134-143. DOI: 10.1145/2934466.2934471

Thurimella, A.K. and B. BruGge, 2013. A mixedmethod approach for the empirical evaluation of the issue-based variability modeling. J. Syst. Software, 86: 1831-1849. DOI: 10.1016/j.jss.2013.01.038

Uzuncaova, E., D. Garcia, S. Khurshid and D. Batory, 2008. Testing software product lines using incremental test generation. Proceedings of the 19th International Symposium on Software Reliability Engineering, Nov. 10-14, IEEE Xplore Press, Seattle, WA, USA, pp: 249-258. DOI: $10.1109 /$ ISSRE.2008.56 
Uzuncaova, E., S. Khurshid and D. Batory, 2010. Incremental test generation for software product lines. IEEE Trans. Software Eng., 36: 309-322. DOI: 10.1109/TSE.2010.30

Villela, K., J. Dorr and I. John, 2010. Evaluation of a method for proactively managing the evolving scope of a software product line. Proceedings of the International Working Conference on Requirements Engineering: Foundation for Software Quality, (FSQ’ 10), Springer, Berlin, pp: 113-127. DOI: $10.1007 / 978-3-642-14192-8 \_13$

Wang, S., S. Ali and A. Gotlieb, 2015. Cost-effective test suite minimization in product lines using search techniques. J. Syst. Software, 103: 370-391. DOI: $10.1016 /$ j.jss.2014.08.024

Wang, S., D. Buchmann, S. Ali, A. Gotlieb and D. Pradhan et al., 2014. Multi-objective test prioritization in software product line testing: An industrial case study. Proceedings of the 18th International Software Product Line Conference, Sept. 15-19, ACM, Florence, Italy, pp: 32-41. DOI: 10.1145/2648511.2648515

Weiss, D.M. and C.T.R. Lai, 1999. Software Productline Engineering: A Family-based Software Development Process. 1st Edn., Addison-Wesley Reading, ISBN-10: 0201694387, pp: 426.

White, J., D. Benavides, D.C. Schmidt, P. Trinidad and B. Dougherty et al., 2010. Automated diagnosis of feature model configurations. J. Syst. Software, 83: 1094-1107. DOI: 10.1016/j.jss.2010.02.017

White, J., J.A. Galindo, T. Saxena, B. Dougherty and D. Benavides et al., 2014. Evolving feature model configurations in software product lines. J. Syst. Software, 87: 119-136.

DOI: $10.1016 /$ j.jss.2013.10.010
White, J., D.C. Schmidt, E. Wuchner and A. Nechypurenko, 2007. Automating product-line variant selection for mobile devices. Proceedings of the 11th International Software Product Line Conference, Sept. 10-14, IEEE Xplore Press, Kyoto, Japan, pp: 129-140. DOI: 10.1109/SPLINE.2007.19

White, J., D.C. Schmidt, E. Wuchner and A. Nechypurenko, 2008. Automatically composing reusable software components for mobile devices. J. Brazilian Comput. Society, 14: 25-44.

DOI: 10.1007/BF03192550

Wohlin, C., P. Runeson, M. Host, M.C. Ohlsson and B. Regnell et al., 2012. Experimentation in Software Engineering. 1st Edn., Springer Science and Business Media, New York, ISBN-10: 3642290442, pp: 236.

Yoshimura, K., T. Forster, D. Muthig and D. Pech, 2008. Model-based design of product line components in the automotive domain. Proceedings of the 12th International Software Product Line Conference, Sept. 8-12, IEEE Xplore Press, Limerick, Ireland, pp: 170-179. DOI: 10.1109/SPLC.2008.20

Yu, L., F. Duan, Y. Lei, R.N. Kacker and D.R. Kuhn, 2014. Combinatorial test generation for software product lines using minimum invalid tuples. Proceedings of the IEEE 15th International Symposium on High-Assurance Systems Engineering, Jan. 9-11, IEEE Xplore Press, Miami Beach, FL, USA, pp: 65-72.

DOI: 10.1109 /HASE.2014.18

\section{Appendix A: Quality evaluation checklist for SE experiments proposed by Kitchenham and Charters (2007)}

Table 6: Part 1 of quality evaluation checklist for SE experiments proposed by Kitchenham and Charters (2007)

\begin{tabular}{|c|c|c|c|c|c|}
\hline Question & $\begin{array}{l}\text { Quantitative } \\
\text { Empirical Studies } \\
\text { (no specific type) }\end{array}$ & $\begin{array}{l}\text { Correlation } \\
\text { (observational } \\
\text { studies) }\end{array}$ & Surveys & Experiments & Source \\
\hline \multicolumn{6}{|l|}{ Design } \\
\hline Are the aims clearly stated? & $\mathrm{X}$ & $\mathrm{X}$ & $\mathrm{X}$ & $\mathrm{X}$ & [11], [10] \\
\hline Was the study designed with these questions in mind? & & & $\mathrm{X}$ & & [25] \\
\hline Do the study measures allow the questions to be answered? & & & $\mathrm{X}$ & $\mathrm{X}$ & {$[10],[25]$} \\
\hline What population was being studied? & & & $\mathrm{X}$ & & [25] \\
\hline Who was included? & & & $\mathrm{X}$ & & [12] \\
\hline Who was excluded? & & & $\mathrm{X}$ & & [12] \\
\hline $\begin{array}{l}\text { How was the sample obtained (e.g. postal, interview, } \\
\text { web-based)? }\end{array}$ & & & $\mathrm{X}$ & & $\begin{array}{l}{[10],[12],} \\
{[25]}\end{array}$ \\
\hline $\begin{array}{l}\text { Is the survey method likely to have introduced } \\
\text { significant bias? }\end{array}$ & & & $\mathrm{X}$ & & {$[25]$} \\
\hline $\begin{array}{l}\text { Is the sample representative of the population to which } \\
\text { the results will generalise? }\end{array}$ & & & $\mathrm{X}$ & $\mathrm{X}$ & {$[10],[25]$} \\
\hline Were treatments randomly allocated? & & & $\mathrm{X}$ & & [10] \\
\hline Is there a comparison or control group? & $\mathrm{X}$ & & $\mathrm{X}$ & $\mathrm{X}$ & [12] \\
\hline $\begin{array}{l}\text { If there is a control group, are participants similar to } \\
\text { the treatment group participants in terms of variables } \\
\text { that may affect study outcomes? }\end{array}$ & $\mathrm{X}$ & & $\mathrm{X}$ & $\mathrm{X}$ & {$[10],[12]$} \\
\hline
\end{tabular}




\begin{tabular}{|c|c|c|c|c|c|}
\hline Was the sample size justified & $\mathrm{X}$ & & $\mathrm{X}$ & $\mathrm{X}$ & {$[10],[12]$} \\
\hline $\begin{array}{l}\text { If the study involves assessment of a technology, is } \\
\text { the technology clearly defined? }\end{array}$ & $\mathrm{X}$ & $\mathrm{X}$ & $\mathrm{X}$ & $\mathrm{X}$ & {$[11]$} \\
\hline $\begin{array}{l}\text { Could the choice of subjects influence the size of the } \\
\text { treatment effect? }\end{array}$ & & & & $\mathrm{X}$ & $\begin{array}{l}{[10],[11],} \\
{[19],[25]}\end{array}$ \\
\hline Could lack of blinding introduce bias? & & & & $\mathrm{X}$ & {$[10]$} \\
\hline $\begin{array}{l}\text { Are the variables used in the study adequately measured } \\
\text { (i.e. are the variables likely to be valid and reliable)? }\end{array}$ & $\mathrm{X}$ & $\mathrm{X}$ & $\mathrm{X}$ & X & $\begin{array}{l}{[10],[11],} \\
{[19],[25]}\end{array}$ \\
\hline
\end{tabular}

Table 7: Part 2 of quality evaluation checklist for SE experimen2t5s proposed by Kitchenham and Charters (2007)

\begin{tabular}{|c|c|c|c|c|c|}
\hline $\begin{array}{l}\text { Are the measures used in the study the most relevant } \\
\text { ones for answering the research questions? }\end{array}$ & $\mathrm{X}$ & $\mathrm{X}$ & $X$ & $\mathrm{X}$ & $\begin{array}{l}{[11],[19],} \\
{[25]}\end{array}$ \\
\hline $\begin{array}{l}\text { Is the scope (size and length) of the study sufficient to allow } \\
\text { for changes in the outcomes of interest to be identified? } \\
\text { Conduct }\end{array}$ & $\mathrm{X}$ & & $\mathrm{X}$ & $\mathrm{X}$ & $\begin{array}{l}{[19],[12],} \\
{[25]}\end{array}$ \\
\hline Did untoward events occur during the study? & $\mathrm{X}$ & $\mathrm{X}$ & $\mathrm{X}$ & $\mathrm{X}$ & {$[10]$} \\
\hline Was outcome assessment blind to treatment group? & $\mathrm{X}$ & & & $\mathrm{X}$ & [19], [12], [25] \\
\hline Are the data collection methods adequately described? & $\mathrm{X}$ & $\mathrm{X}$ & $\mathrm{X}$ & $\mathrm{X}$ & [11] \\
\hline $\begin{array}{l}\text { If two groups are being compared, were they treated } \\
\text { similarly within the study? }\end{array}$ & & & & $\mathrm{X}$ & {$[12],[25]$} \\
\hline $\begin{array}{l}\text { If the study involves participants over time, what proportion } \\
\text { of people who enrolled at the beginning dropped out? }\end{array}$ & $\mathrm{X}$ & & $\mathrm{X}$ & $\mathrm{X}$ & {$[10],[11]$} \\
\hline How was the randomisation carried out? & & & & $\mathrm{X}$ & [10] \\
\hline Analysis & & & & & \\
\hline What was the response rate? & & & $\mathrm{X}$ & & {$[10],[25]$} \\
\hline Was the denominator (i.e. the population size) reported? & & & $\mathrm{X}$ & & {$[25]$} \\
\hline $\begin{array}{l}\text { Do the researchers explain the data types (continuous, } \\
\text { ordinal, categorical)? }\end{array}$ & $\mathrm{X}$ & $X$ & $\mathrm{X}$ & $\mathrm{X}$ & [11] \\
\hline $\begin{array}{l}\text { Are the study participants or observational units adequately } \\
\text { described? For example, SE experience, type (student, } \\
\text { practitioner, consultant), nationality, task experience and } \\
\text { other relevant variables. }\end{array}$ & $\mathrm{X}$ & $X$ & $\mathrm{X}$ & $\mathrm{X}$ & {$[12],[25]$} \\
\hline Were the basic data adequately described? & $\mathrm{X}$ & $\mathrm{X}$ & $\mathrm{X}$ & $\mathrm{X}$ & {$[10]$} \\
\hline Have "drop outs" introduced bias? & $\mathrm{X}$ & & $\mathrm{X}$ & $\mathrm{X}$ & {$[11],[12],[25]$} \\
\hline Are reasons given for refusal to participate? & $\mathrm{X}$ & & $\mathrm{X}$ & $\mathrm{X}$ & [11] \\
\hline Are the statistical methods described? & $\mathrm{X}$ & $\mathrm{X}$ & $\mathrm{X}$ & $\mathrm{X}$ & {$[10],[11],[19]$} \\
\hline $\begin{array}{l}\text { Is the statistical program used to analyse the data } \\
\text { referenced? }\end{array}$ & $\mathrm{X}$ & $\mathrm{X}$ & $\mathrm{X}$ & $\mathrm{X}$ & {$[11]$} \\
\hline Are the statistical methods justified? & $\mathrm{X}$ & $\mathrm{X}$ & $\mathrm{X}$ & $\mathrm{X}$ & [11] \\
\hline Is the purpose of the analysis clear? & $\mathrm{X}$ & $\mathrm{X}$ & $\mathrm{X}$ & $\mathrm{X}$ & [11] \\
\hline Are scoring systems described? & $\mathrm{X}$ & & & $\mathrm{X}$ & [11] \\
\hline $\begin{array}{l}\text { Are potential confounders adequately controlled for } \\
\text { in the analysis? }\end{array}$ & $\mathrm{X}$ & $\mathrm{X}$ & $\mathrm{X}$ & $X$ & [11] \\
\hline Do the numbers add up across different tables and & $\mathrm{X}$ & $\mathrm{X}$ & $\mathrm{X}$ & $\mathrm{X}$ & {$[10],[11]$} \\
\hline
\end{tabular}

Table 8: Part 3 of quality evaluation checklist for SE experiments proposed by Kitchenham and Charters (2007)

subgroups?

If different groups were different at the start of the study

$\mathrm{X}$

$\mathrm{X}$

$\mathrm{X}$

[12], [25]

or treated differently during the study, was any attempt

made to control for these differences, either statistically

or by matching?

If yes, was it successful?

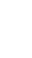

Was statistical significance assessed?

If statistical tests are used to determine differences, is

the actual $\mathrm{p}$ value given?

If the study is concerned with differences among groups,

are confidence limits given describing the magnitude

of any observed differences?

Is there evidence of multiple statistical testing or

large numbers of post hoc analysis?

How could selection bias arise?

Were side-effects reported?

$\mathrm{X}$

$\mathrm{X}$

X

$\mathrm{X}$

$\mathrm{X}$

Are all study questions answered?

What do the main findings mean?

Are negative findings presented?

If statistical tests are used to determine differences,

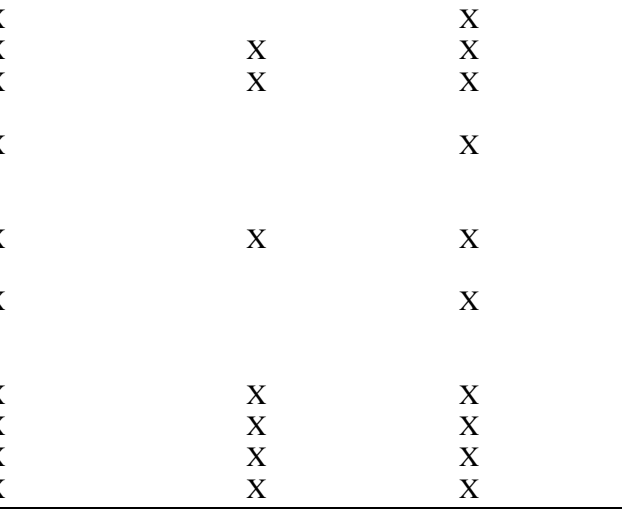

[11]

[10]

[11] 
is practical significance discussed?

If drop outs differ from participants, are limitations $\quad \mathrm{X}$

to the results discussed?

How are null findings interpreted? (I.e. has the possibility

that the sample size is too small been considered?)

Are important effects overlooked?

How do results compare with previous reports?

How do the results add to the literature?

What implications does the report have for practice?

Do the researchers explain the consequences of any

problems with the validity/reliability of their measures?

$\begin{array}{lllll}X & X & X & {[11]} \\ X & X & X & X & {[10],[12]} \\ X & X & X & X & {[10]} \\ X & X & X & X & {[10]} \\ X & X & X & X & {[12]} \\ X & X & X & X & {[10]} \\ X & X & X & X & {[11]}\end{array}$

\section{Appendix B: Quality evaluation checklist for SE experiments proposed by Kampenes (2007)}

Table 9: Quality evaluation checklist for SE experiments proposed by Kampenes (2007)

\begin{tabular}{|c|c|c|c|c|}
\hline \multirow[b]{2}{*}{ Information attributes } & \multirow[b]{2}{*}{ Variables } & \multicolumn{3}{|c|}{ Extent of reporting. Number of experiments } \\
\hline & & $\mathrm{N}$ & Total & $\%$ \\
\hline \multirow[t]{9}{*}{ Subjects } & Sample size & 113 & 113 & 100 \\
\hline & Mortality rate & 24 & 113 & 21.2 \\
\hline & Type (student/professionals) & 112 & 113 & 99.1 \\
\hline & Recruitment (Voluntarily/mandatory) & 41 & 113 & 36.3 \\
\hline & Some kind of background information & 99 & 113 & 87.6 \\
\hline & - Programming experience & 37 & 113 & 32.7 \\
\hline & - Work experience & 24 & 113 & 21.2 \\
\hline & - Task related experience & 80 & 113 & 70.8 \\
\hline & - Grades & 6 & 113 & 5.3 \\
\hline \multirow[t]{6}{*}{ Experimental setting } & Task & 113 & 113 & 100.0 \\
\hline & Duration & 69 & 113 & 61.1 \\
\hline & Application system & 101 & 113 & 89.4 \\
\hline & Size of materials & 67 & 113 & 59.3 \\
\hline & Location & 40 & 113 & 35.4 \\
\hline & The use of tools & 62 & 113 & 54.9 \\
\hline \multirow[t]{6}{*}{ Design and analysis } & Well-defined population & 1 & 113 & 0.9 \\
\hline & Statistical power & 1 & 92 & 1.1 \\
\hline & Effect size $*$ & 27 & 92 & 29.3 \\
\hline & $\begin{array}{l}\text { Information available for estimation of at least } \\
\text { one effect size }\end{array}$ & 64 & 92 & 69.6 \\
\hline & Assignment procedure (randomized or quasi) & 86 & 113 & 76.1 \\
\hline & Randomization method & 3 & 66 & 4.5 \\
\hline \multirow[t]{5}{*}{ Validity/limitations } & Discussion of internal validity & 71 & 113 & 62.8 \\
\hline & Threats to internal validity & 26 & 113 & 23.0 \\
\hline & Discussion of external validity & 78 & 113 & 69.0 \\
\hline & Discussing of statistical conclusion validity $\dagger$ & 5 & 99 & 5.1 \\
\hline & Discussion of construct validity $\dagger$ & 12 & 113 & 10.6 \\
\hline
\end{tabular}

Note: Which experiments and articles that are included in these assessments is described in Appendix A; * Extent of reporting refers to the number of experiments with at least one effect size reported; $\uparrow$ The number of experiments that discuss statistical conclusion validity and/or construct validity is based on the explicit use of these terms. The reporting of these types of validity needs to be investigated more thoroughly in future work.

\section{Appendix C: Quality evaluation checklist for SE experiments proposed by Kitchenham et al. (2010)}

Table 10: Quality evaluation checklist for SE experiments proposed by Kitchenham et al. (2010)

\begin{tabular}{ll}
\hline$\# \quad$ Question & Things to consider \\
\hline $\begin{array}{l}\text { Category: Questions on Aims } \\
\text { 1. Do the authors clearly state }\end{array}$ & $\begin{array}{l}\text { Do the authors state research questions, e.g., related to time-to-market, cost, product quality, } \\
\text { process quality, developer productivity and developer skills? } \\
\text { Do aims of the research? }\end{array}$ \\
$\begin{array}{ll}\text { Category: Questions on Design, Data Collection and Data Analysis } \\
\text { 2. Do the authors describe the }\end{array}$ \\
$\begin{array}{ll}\text { sample and experimental } \\
\text { units (=experimental }\end{array}$ & Do the authors explain how experimental units were defined and selected? \\
\end{tabular}




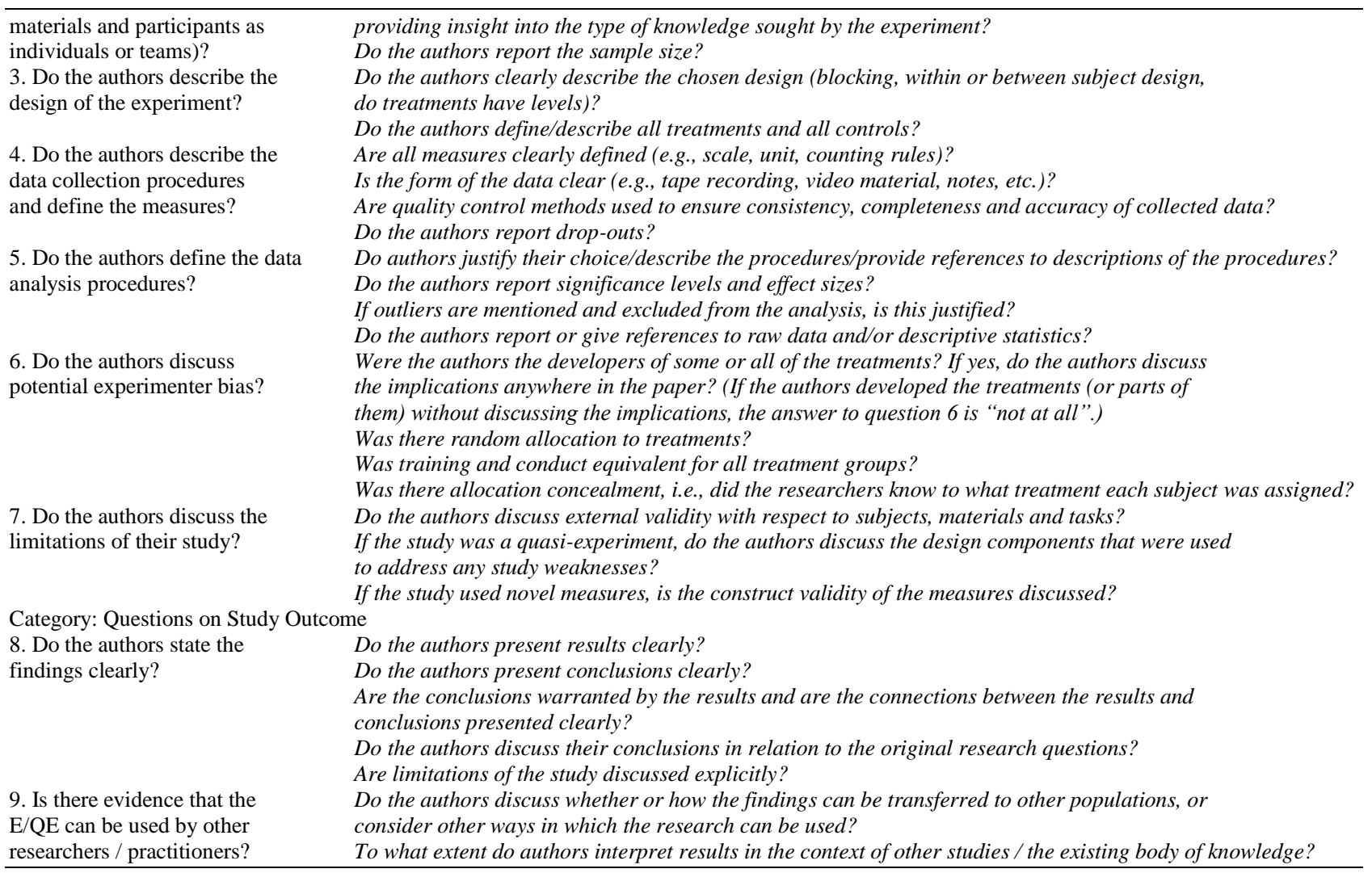

\section{Appendix D: Quality scale to evaluate for SE experiments proposed by Dieste et al. (2011)}

Table 11: Quality scale to evaluate for SE experiments proposed by Dieste et al. (2011)

\begin{tabular}{|c|c|c|}
\hline Dimension & Question & Recommendation \\
\hline \multirow[t]{3}{*}{$\begin{array}{l}\text { Experimental } \\
\text { Context }\end{array}$} & $\begin{array}{l}\text { Does the introduction contain the } \\
\text { industrial context (entities, attributes and } \\
\text { measures) and description of the } \\
\text { techniques to be reviewed? For } \\
\text { experiments that evaluate techniques } \\
\text { developed in industry. (Q1) }\end{array}$ & $\begin{array}{l}\text { In experiments evaluating techniques developed in industry, experimenters } \\
\text { should understand how the technique works in the industrial setting before } \\
\text { developing a version of the technique for experimental purposes. This is due } \\
\text { to the fact that techniques developed in industrial settings are highly complex, } \\
\text { and such complexity is difficult to reproduce in academia. } \\
\text { The treatments that are tested in an experiment must be well defined in the } \\
\text { report for the experiment to be able to be replicated or simply for the results to } \\
\text { be able to be transferred to industry. }\end{array}$ \\
\hline & $\begin{array}{l}\text { Does the report summarize and discuss } \\
\text { earlier similar experiments that have been } \\
\text { conducted? (Q2) }\end{array}$ & $\begin{array}{l}\text { Describing earlier research that is similar to this study and how they are } \\
\text { related can help to build an integrated body of knowledge about a } \\
\text { phenomenon in SE. }\end{array}$ \\
\hline & $\begin{array}{l}\text { Are the hypotheses being laid and are they } \\
\text { synonymous with the goal discussed } \\
\text { before in introduction? (Q3) }\end{array}$ & $\begin{array}{l}\text { Specific hypotheses that are being tested in the study should be clearly } \\
\text { established beforehand based on a theory. }\end{array}$ \\
\hline \multirow[t]{5}{*}{$\begin{array}{l}\text { Experimental } \\
\text { Design }\end{array}$} & $\begin{array}{l}\text { Does the researcher define the population } \\
\text { from which objects and subjects are } \\
\text { drawn? (Q4) }\end{array}$ & $\begin{array}{l}\text { It is necessary to define the population from which the subjects and objects } \\
\text { have been extracted to be able to extract inferences from the experimental } \\
\text { results. }\end{array}$ \\
\hline & $\begin{array}{l}\text { Does the researcher define the process by } \\
\text { which he applies the treatment to objects } \\
\text { and subjects (e.g. randomization)? (Q6) }\end{array}$ & $\begin{array}{l}\text { The subjects and objects should be allocated to the treatments in an unbiased } \\
\text { manner so as not to compromise the experiment. }\end{array}$ \\
\hline & $\begin{array}{l}\text { Was randomization used for selecting the } \\
\text { population and applying the treatment? } \\
\text { (Q7) }\end{array}$ & $\begin{array}{l}\text { The subjects and objects should be representative of the population to be able } \\
\text { to extract conclusions from the experimental results. }\end{array}$ \\
\hline & $\begin{array}{l}\text { Does the researcher define the process } \\
\text { from which the objects and subjects are } \\
\text { selected (e.g. random sampling)? (Q5) }\end{array}$ & \\
\hline & $\begin{array}{l}\text { Is an appropriate blinding procedure used } \\
\text { (e.g. blind allocation of materials, blind } \\
\text { marking)? (Q10) }\end{array}$ & $\begin{array}{l}\text { A double-blinding procedure, as run in medicine, is not possible in SE } \\
\text { experiments, but other types of blinding are; these types of blinding can be } \\
\text { applied to the allocation of materials, marking and analysis. }\end{array}$ \\
\hline Analysis & Is an appropriate blinding procedure used & The information on treatments should be somehow encoded to prevent \\
\hline
\end{tabular}




\begin{tabular}{lll}
\hline & (e.g. blind allocation of materials, blind & $\begin{array}{l}\text { analysts from knowing the treatment to which it corresponds and being able to } \\
\text { marking)? (Q10) }\end{array}$ \\
$\begin{array}{l}\text { Presentation } \\
\text { of results }\end{array}$ & $\begin{array}{l}\text { Are the statistical significances mentioned } \\
\text { with the results. (Q9) }\end{array}$ & $\begin{array}{l}\text { The experiment should report the quantitative data including the effect size } \\
\text { and the confidence limits. }\end{array}$ \\
$\begin{array}{l}\text { of results } \\
\text { Is mention made of the threats to validity }\end{array}$ & $\begin{array}{l}\text { Experimenters should discuss the limits of the study, at least threats related to } \\
\text { internal and external validity. }\end{array}$ \\
& $\begin{array}{l}\text { and also how these threats affect the } \\
\text { results and findings? }(\mathbf{Q 8})\end{array}$ \\
\hline
\end{tabular}

\section{Appendix E: Selected primary studies}

Table 12: Selected Primary Studies

\begin{tabular}{|c|c|c|c|c|c|}
\hline ID & Title & Author(s) & Year & $\begin{array}{l}\text { Publication } \\
\text { Type }\end{array}$ & $\begin{array}{l}\text { Publication } \\
\text { Venue }\end{array}$ \\
\hline $\mathrm{S} 1$ & $\begin{array}{l}\text { A Comparative Analysis of Two } \\
\text { Multi-objective Evolutionary Algorithms } \\
\text { in Product Line Architecture Design } \\
\text { Optimization }\end{array}$ & Colanzi and Vergilio (2014a) & 2014 & Conference & ICTAI \\
\hline $\mathrm{S} 2$ & $\begin{array}{l}\text { A Comparison of Product-based, Featurebased, } \\
\text { and Family-based Type Checking }\end{array}$ & Kolesnikov et al. (2014) & 2014 & Conference & GPCE \\
\hline S3 & $\begin{array}{l}\text { A Cover-based Approach for Configuration } \\
\text { Repair }\end{array}$ & Barreiros and Moreira (2014) & 2014 & Conference & SPLC \\
\hline S4 & $\begin{array}{l}\text { A feature-driven crossover operator for } \\
\text { multi-objective and evolutionary } \\
\text { optimization of product line architectures }\end{array}$ & Colanzi and Vergilio (2016) & 2016 & Journal & JSS \\
\hline S5 & $\begin{array}{l}\text { A Feature-Driven Crossover Operator } \\
\text { for Product Line Architecture Design } \\
\text { Optimization }\end{array}$ & Colanzi and Vergilio (2014b) & 2014 & Conference & COMPSAC \\
\hline S6 & $\begin{array}{l}\text { A genetic algorithm for optimized } \\
\text { feature selection with resource } \\
\text { constraints in software product lines }\end{array}$ & Guo et al. (2011) & 2011 & Journal & JSS \\
\hline S7 & $\begin{array}{l}\text { A hybrid approach to suggest software } \\
\text { product line portfolios }\end{array}$ & Santos Neto et al. (2016) & 2016 & Journal & $\begin{array}{l}\text { Applied Soft } \\
\text { Computing }\end{array}$ \\
\hline S8 & $\begin{array}{l}\text { A mixed-method approach for the } \\
\text { empirical evaluation of the issuebased } \\
\text { variability modeling }\end{array}$ & Thurimella and BruGge (2013) & 2013 & Journal & JSS \\
\hline S9 & $\begin{array}{l}\text { A performance comparison of } \\
\text { contemporary algorithmic approaches } \\
\text { for automated analysis operations on } \\
\text { feature models }\end{array}$ & Pohl et al. (2011) & 2011 & Conference & ASE \\
\hline S10 & $\begin{array}{l}\text { A preliminary experimental study on } \\
\text { optimal feature selection for product } \\
\text { derivation using knapsack approximation }\end{array}$ & Shi et al. (2010) & 2010 & Conference & PIC \\
\hline S11 & $\begin{array}{l}\text { A Preliminary Study on the Effects of } \\
\text { Working with a Testing Process in } \\
\text { Software Product Line Projects }\end{array}$ & Machado et al. (2012) & 2012 & Conference & ESELAW \\
\hline $\mathrm{S} 12$ & $\begin{array}{l}\text { A Regression Testing Approach for } \\
\text { Software Product Lines Architectures }\end{array}$ & Silveira Neto et al. (2010) & 2010 & Conference & SBCARS \\
\hline S13 & $\begin{array}{l}\text { A Scalable Approach to Exact Model } \\
\text { and Commonality Counting for } \\
\text { Extended Feature Models }\end{array}$ & Fernandez-Amoros et al. (2014) & 2014 & Journal & $\begin{array}{l}\text { IEEE Transactions } \\
\text { on Software } \\
\text { Engineering }\end{array}$ \\
\hline S14 & $\begin{array}{l}\text { A Set of Inspection Techniques on } \\
\text { Software Product Line Models }\end{array}$ & Cunha et al. (2012) & 2012 & Conference & SEKE \\
\hline S15 & $\begin{array}{l}\text { A software cost estimation model for } \\
\text { a product line engineering approach: } \\
\text { supporting tool and UML modeling }\end{array}$ & Lamine et al. (2005) & 2005 & Conference & SERA \\
\hline S16 & $\begin{array}{l}\text { A software product lines system test case } \\
\text { tool and its initial evaluation }\end{array}$ & Neto et al. (2012) & 2012 & Conference & IRI \\
\hline S17 & $\begin{array}{l}\text { A Systems Approach to Product Line } \\
\text { Requirements Reuse }\end{array}$ & Niu et al. (2014) & 2014 & Journal & $\begin{array}{l}\text { IEEE Systems } \\
\text { Journal }\end{array}$ \\
\hline S18 & A Toolset for Checking SPL Refinements & Ferreira et al. (2014) & 2014 & Journal & JUCS \\
\hline S19 & $\begin{array}{l}\text { A use case textual description for context } \\
\text { aware SPL based on a controlled } \\
\text { experiment }\end{array}$ & Santos et al. (2013) & 2013 & Journal & CAiSE \\
\hline $\mathrm{S} 20$ & Actor in multi product line & Rahmat et al. (2016) & 2016 & Conference & IMCOM \\
\hline $\mathrm{S} 21$ & $\begin{array}{l}\text { Adoption of software product line to a } \\
\text { voice user interface environment }\end{array}$ & Oliveira et al. (2015) & 2015 & Conference & SEKE \\
\hline S22 & $\begin{array}{l}\text { An Algorithm for Generating T-wise } \\
\text { Covering Arrays from Large Feature } \\
\text { Models }\end{array}$ & Johansen et al. (2012) & 2012 & Conference & SPLC \\
\hline
\end{tabular}




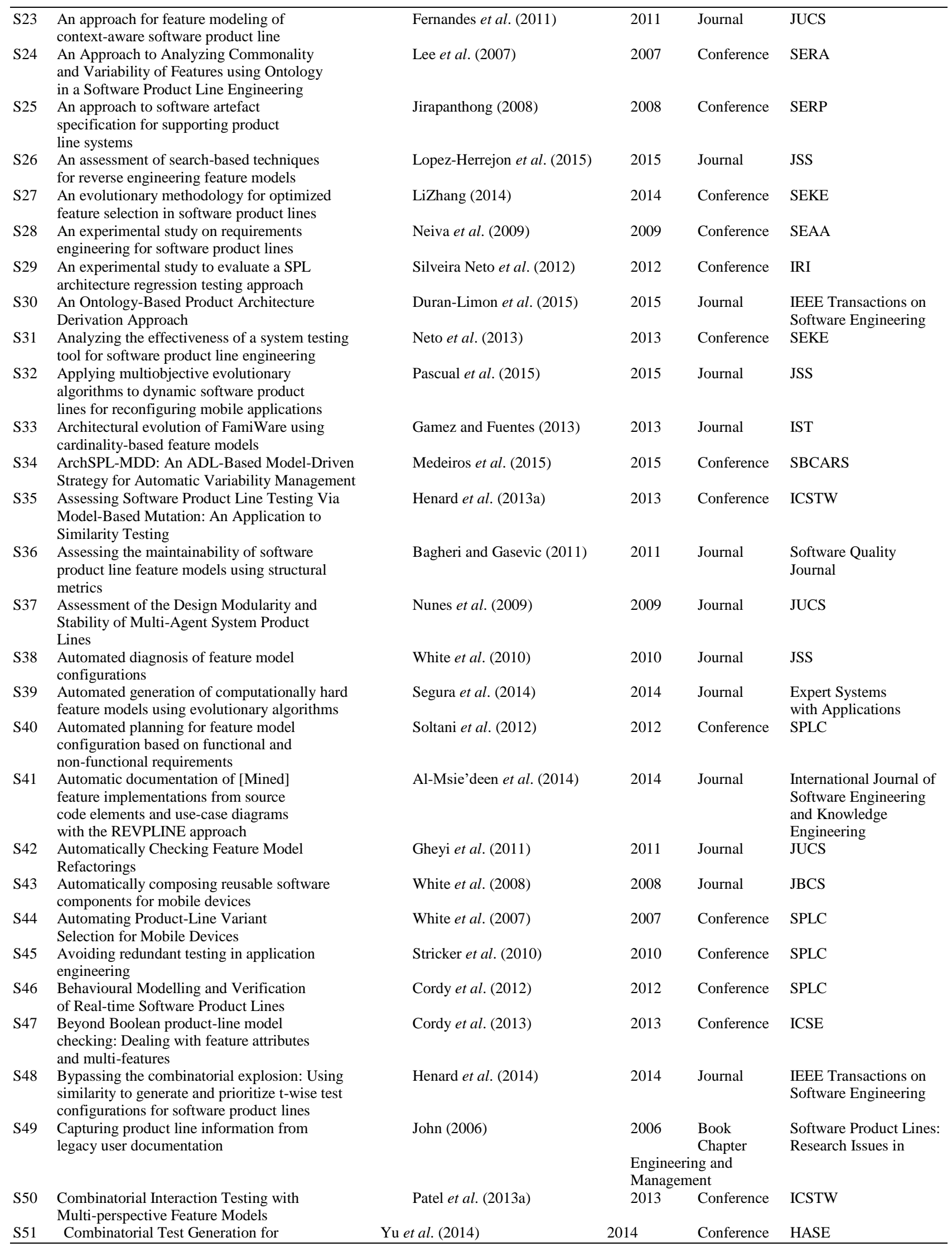




\begin{tabular}{|c|c|c|c|c|c|}
\hline & $\begin{array}{l}\text { Software Product Lines Using } \\
\text { Minimum Invalid Tuples }\end{array}$ & & & & \\
\hline S52 & $\begin{array}{l}\text { Combinatorial Testing for Feature } \\
\text { Models Using CitLab }\end{array}$ & Calvagna et al. (2013) & 2013 & Conference & ICSTW \\
\hline S53 & $\begin{array}{l}\text { Combining Multi-Objective Search } \\
\text { and Constraint Solving for Configuring } \\
\text { Large Software Product Lines }\end{array}$ & Henard et al. (2015) & 2015 & Conference & ICSE \\
\hline S54 & $\begin{array}{l}\text { Comparing Two Black-Box Testing } \\
\text { Strategies for Software Product Lines }\end{array}$ & Accioly et al. (2012) & 2012 & Conference & SBCARS \\
\hline S55 & $\begin{array}{l}\text { Comparison of Exact and Approximate } \\
\text { Multi-objective Optimization for } \\
\text { Software Product Lines }\end{array}$ & Olaechea et al. (2014) & 2014 & Conference & SPLC \\
\hline S56 & $\begin{array}{l}\text { Comprehending feature models } \\
\text { expressed in CVL }\end{array}$ & Reinhartz-Berger et al. (2014a) & 2014 & Conference & MODELS \\
\hline S57 & $\begin{array}{l}\text { Comprehensibility of UML-based } \\
\text { software product line specifications } \\
\text { A controlled experiment }\end{array}$ & $\begin{array}{l}\text { Reinhartz-Berger and } \\
\text { Sturm }(2014 b)\end{array}$ & 2014 & Journal & $\begin{array}{l}\text { Empirical Software } \\
\text { Engineering }\end{array}$ \\
\hline S58 & $\begin{array}{l}\text { Conditioned model slicing of } \\
\text { feature-annotated state machines }\end{array}$ & Kamischke et al. (2012) & 2012 & Conference & FOSD \\
\hline S59 & $\begin{array}{l}\text { Configuration knowledge of software } \\
\text { product lines: A comprehensibility study }\end{array}$ & Cirilo et al. (2011) & 2011 & Conference & VariComp \\
\hline S60 & $\begin{array}{l}\text { Consistency maintenance for evolving } \\
\text { feature models }\end{array}$ & Guo et al. (2012) & 2012 & Journal & $\begin{array}{l}\text { Expert Systems } \\
\text { with Applications }\end{array}$ \\
\hline S61 & $\begin{array}{l}\text { Controlled experiments comparing } \\
\text { black-box testing strategies for software } \\
\text { product lines }\end{array}$ & Accioly et al. (2014) & 2014 & Journal & JUCS \\
\hline S62 & $\begin{array}{l}\text { Cost-effective test suite minimization } \\
\text { in product lines using search techniques }\end{array}$ & Wang et al. (2015) & 2015 & Journal & JSS \\
\hline S63 & $\begin{array}{l}\text { Counterexample Guided Abstraction } \\
\text { Refinement of product-line behavioural models }\end{array}$ & Cordy et al. (2014) & 2014 & Conference & FSE \\
\hline S64 & $\begin{array}{l}\text { Decision support for the software product } \\
\text { line domain engineering lifecycle }\end{array}$ & Bagheri et al. (2012a) & 2012 & Journal & $\begin{array}{l}\text { Automated Software } \\
\text { Engineering }\end{array}$ \\
\hline S65 & $\begin{array}{l}\text { Defining and validating a multimodel } \\
\text { approach for product architecture } \\
\text { derivation and improvement }\end{array}$ & Gonzalez-Huerta et al. (2013) & 2013 & Conference & MODELS \\
\hline S66 & $\begin{array}{l}\text { Delta-oriented model-based SPL } \\
\text { regression testing }\end{array}$ & Lity et al. (2012) & 2012 & Conference & PLEASE \\
\hline S67 & $\begin{array}{l}\text { Designing a Set of Service-Oriented } \\
\text { Systems as a Software Product Line }\end{array}$ & Medeiros et al. (2010a) & 2010 & Conference & SBCARS \\
\hline S68 & $\begin{array}{l}\text { Do background colors improve program } \\
\text { comprehension in the \#ifdef hell? }\end{array}$ & Feigenspan et al. (2013) & 2013 & Journal & $\begin{array}{l}\text { Empirical Software } \\
\text { Engineering }\end{array}$ \\
\hline S69 & $\begin{array}{l}\text { Domain implementation in software } \\
\text { product lines using OSGi }\end{array}$ & Almeida et al. (2008) & 2008 & Conference & ICCBSS \\
\hline S70 & $\begin{array}{l}\text { Effective requirements elicitation in product } \\
\text { line application engineering- An experiment }\end{array}$ & Adam and Schmid (2013) & 2013 & Conference & REFSQ \\
\hline S71 & $\begin{array}{l}\text { Effects of stability on model composition } \\
\text { effort: an exploratory study }\end{array}$ & Farias et al. (2014) & 2014 & Journal & $\begin{array}{l}\text { Software \& Systems } \\
\text { Modeling }\end{array}$ \\
\hline S72 & Efficient synthesis of feature models & Andersen et al. (2012) & 2014 & Journal & IST \\
\hline S73 & $\begin{array}{l}\text { Empirical assessment of two } \\
\text { approaches for specifying software } \\
\text { product line use case scenarios }\end{array}$ & Bonifacio et al. (2017) & 2015 & Journal & $\begin{array}{l}\text { Software \& Systems } \\
\text { Modeling }\end{array}$ \\
\hline S74 & $\begin{array}{l}\text { Empirical validating the cognitive } \\
\text { effectiveness of a new feature } \\
\text { diagrams visual syntax }\end{array}$ & Saeed et al. (2016) & 2016 & Journal & IST \\
\hline S75 & $\begin{array}{l}\text { Empirical Validation of Complexity } \\
\text { and Extensibility Metrics for } \\
\text { Software Product Line Architetures }\end{array}$ & OliveiraJr et al. (2010) & 2010 & Conference & SBCARS \\
\hline S76 & $\begin{array}{l}\text { Empirical Validation of Variabilitybased } \\
\text { Complexity Metrics for } \\
\text { Software Product Line Architecture }\end{array}$ & OliveiraJr et al. (2012) & 2012 & Conference & SEKE \\
\hline S77 & $\begin{array}{l}\text { Empirically Based Evolution of a } \\
\text { Variability Management Approach } \\
\text { at UML Class Level }\end{array}$ & Marcolino et al. (2014b) & 2014 & Conference & COMPSAC \\
\hline S78 & $\begin{array}{l}\text { Evaluating the representation of user interface } \\
\text { elements in feature models: An empirical study }\end{array}$ & Rodrigues et al. (2016) & 2016 & Conference & SEKE \\
\hline S79 & $\begin{array}{l}\text { Evaluating the usability of a visual } \\
\text { feature modeling notation }\end{array}$ & Jaksic et al. (2014) & 2014 & Conference & SLE \\
\hline S80 & $\begin{array}{l}\text { Evaluating Variability Instantiation } \\
\text { Strategies for Product Lines }\end{array}$ & John and Silva (2011) & 2011 & Conference & VaMoS \\
\hline
\end{tabular}




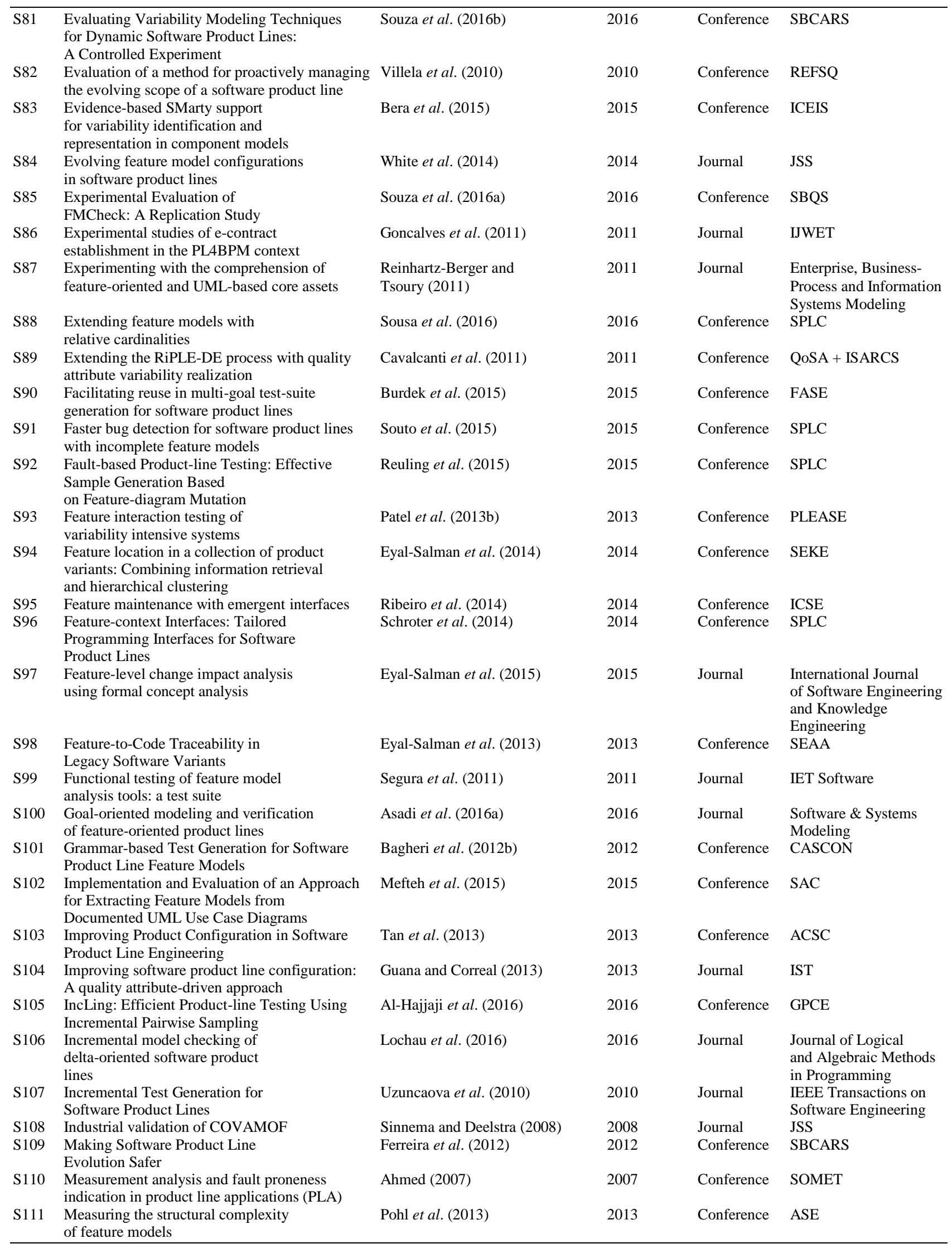




\begin{tabular}{|c|c|c|c|c|c|}
\hline S112 & $\begin{array}{l}\text { Model-Based Design of Product Line } \\
\text { Components in the Automotive Domain }\end{array}$ & Yoshimura et al. (2008) & 2008 & Conference & SPLC \\
\hline S113 & $\begin{array}{l}\text { Model-based verification of quantitative } \\
\text { non-functional properties for software } \\
\text { product lines }\end{array}$ & Ghezzi and Sharifloo (2013) & 2013 & Journal & IST \\
\hline S114 & $\begin{array}{l}\text { Modeling and Verification for Probabilistic } \\
\text { Properties in Software Product Lines }\end{array}$ & Rodrigues et al. (2015) & 2015 & Conference & HASE \\
\hline S115 & $\begin{array}{l}\text { Multi-objective test generation for } \\
\text { software product lines }\end{array}$ & Henard et al. (2013b) & 2013 & Conference & SPLC \\
\hline S116 & $\begin{array}{l}\text { Multi-objective Test Prioritization } \\
\text { in Software Product Line Testing: } \\
\text { An Industrial Case Study }\end{array}$ & Wang et al. (2014) & 2014 & Conference & SPLC \\
\hline S117 & $\begin{array}{l}\text { On Extracting Feature Models from } \\
\text { Product Descriptions }\end{array}$ & Acher et al. (2012) & 2012 & Conference & VaMoS \\
\hline S118 & $\begin{array}{l}\text { On the relationship of concern metrics } \\
\text { and requirements maintainability }\end{array}$ & Conejero et al. (2012) & 2012 & Journal & IST \\
\hline S119 & $\begin{array}{l}\text { On the value of user preferences in } \\
\text { search-based software engineering: } \\
\text { A case study in software product lines }\end{array}$ & Sayyad et al. (2013) & 2013 & Conference & ICSE \\
\hline S120 & $\begin{array}{l}\text { Ontology-based feature modeling: An } \\
\text { empirical study in changing scenarios }\end{array}$ & Dermeval et al. (2015) & 2015 & Journal & $\begin{array}{l}\text { Expert Systems } \\
\text { with Applications }\end{array}$ \\
\hline S121 & $\begin{array}{l}\text { Optimized feature selection towards } \\
\text { functional and non-functional } \\
\text { requirements in Software Product Lines }\end{array}$ & Lian and Zhang (2015) & 2015 & Conference & SANER \\
\hline S122 & $\begin{array}{l}\text { Optimizing software product line } \\
\text { architectures with OPLA-tool }\end{array}$ & Federle et al. (2015) & 2015 & Conference & SSBSE \\
\hline S123 & $\begin{array}{l}\text { PACOGEN: Automatic Generation of Pairwise } \\
\text { Test Configurations from Feature Models }\end{array}$ & Hervieu et al. (2011) & 2011 & Conference & ISSRE \\
\hline S124 & $\begin{array}{l}\text { Potential synergies of theorem proving and } \\
\text { model checking for software product lines }\end{array}$ & Thum et al. (2014) & 2014 & Conference & SPLC \\
\hline S125 & $\begin{array}{l}\text { Practical minimization of pairwisecovering test } \\
\text { configurations using constraint programming }\end{array}$ & Hervieu et al. (2016) & 2017 & Journal & IST \\
\hline S126 & $\begin{array}{l}\text { Practical pairwise testing for } \\
\text { software product lines }\end{array}$ & Marijan et al. (2013) & 2013 & Conference & SPLC \\
\hline S127 & $\begin{array}{l}\text { Preference-based Feature Model Configuration } \\
\text { with Multiple Stakeholders }\end{array}$ & Stein et al. (2014) & 2014 & Conference & SPLC \\
\hline S128 & $\begin{array}{l}\text { Preserving architectural styles in } \\
\text { the search based design of software } \\
\text { product line architectures }\end{array}$ & Mariani et al. (2016) & 2016 & Journal & JSS \\
\hline S129 & $\begin{array}{l}\text { Product Line Variability Modeling Based } \\
\text { on Model Difference and Merge }\end{array}$ & Nie et al. (2012) & 2012 & Conference & COMPSAC \\
\hline S130 & $\begin{array}{l}\text { Product-line maintenance with } \\
\text { emergent contract interfaces }\end{array}$ & Thum et al. (2016) & 2016 & Conference & SPLC \\
\hline S131 & Reasoning about edits to feature models & Thum et al. (2009) & 2009 & Conference & ICSE \\
\hline S132 & $\begin{array}{l}\text { Reasoning about product-line evolution } \\
\text { using complex feature model differences }\end{array}$ & Burdek et al. (2016) & 2016 & Journal & $\begin{array}{l}\text { Automated Software } \\
\text { Engineering }\end{array}$ \\
\hline S133 & $\begin{array}{l}\text { Recovering Architectural Variability } \\
\text { of a Family of Product Variants }\end{array}$ & Shatnawi et al. (2015) & 2015 & Conference & ICSR \\
\hline S134 & $\begin{array}{l}\text { Refactoring the documentation of } \\
\text { software product lines }\end{array}$ & Romanovsky et al. (2011) & 2011 & Conference & CEE-SET \\
\hline S135 & Relating Requirement and Design Variabilities & Millo and Ramesh (2012) & 2012 & Conference & APSEC \\
\hline S136 & $\begin{array}{l}\text { Requirements Evolution in Software } \\
\text { Product Lines: An Empirical Study }\end{array}$ & Oliveira and Almeida (2015) & 2015 & Conference & SBCARS \\
\hline S137 & $\begin{array}{l}\text { RiPLE-HC: JavaScript systems meets } \\
\text { SPL composition }\end{array}$ & Santos et al. (2016) & 2016 & Conference & SPLC \\
\hline S138 & $\begin{array}{l}\text { RiPLE-TE: A process for testing } \\
\text { Software Product Lines }\end{array}$ & Machado et al. (2011) & 2011 & Conference & SEKE \\
\hline S139 & $\begin{array}{l}\text { Scalable prediction of non-functional properties } \\
\text { in software product lines: Footprint and } \\
\text { memory consumption }\end{array}$ & Siegmund et al. (2013) & 2013 & Journal & IST \\
\hline S140 & Scoping automation in software product lines & Ianzen et al. (2015) & 2015 & Conference & ICEIS \\
\hline S141 & $\begin{array}{l}\text { Search Based Design of Layered } \\
\text { Product Line Architectures }\end{array}$ & Mariani et al. (2015) & 2015 & Conference & COMPSAC \\
\hline S142 & $\begin{array}{l}\text { Search-based Test Case Selection } \\
\text { of Cyber-physical System Product } \\
\text { Lines for Simulation-based Validation }\end{array}$ & Arrieta et al. (2016) & 2016 & Conference & SPLC \\
\hline S143 & $\begin{array}{l}\text { Shared Execution for Efficiently } \\
\text { Testing Product Lines }\end{array}$ & Akim et al. (2012) & 2012 & Conference & ISSRE \\
\hline S144 & $\begin{array}{l}\text { Similarity-based prioritization in } \\
\text { software product-line testing }\end{array}$ & Al-Hajjaji et al. (2014) & 2014 & Conference & SPLC \\
\hline S145 & SIP: Optimal product selection from feature & Hierons et al. (2016) & 2016 & Journal & TOSEM \\
\hline
\end{tabular}




\begin{tabular}{|c|c|c|c|c|c|}
\hline & models using manyobjective evolutionary optim & ation & & & \\
\hline S146 & $\begin{array}{l}\text { SOPLE-DE: An approach to design service- } \\
\text { oriented product line architectures }\end{array}$ & Medeiros et al. (2010b) & 2010 & Conference & SPLC \\
\hline S147 & $\begin{array}{l}\text { SPLat: Lightweight dynamic analysis for } \\
\text { reducing combinatorics in testing } \\
\text { configurable systems }\end{array}$ & Kim et al. (2013) & 2013 & Conference & ESEC/FSE \\
\hline S148 & $\begin{array}{l}\text { SPLLIFT- Statically analyzing software } \\
\text { product lines in minutes instead of years }\end{array}$ & Bodden et al. (2014) & 2014 & Conference & PLDI \\
\hline S149 & $\begin{array}{l}\text { Strategies for product-line verification: } \\
\text { Case studies and experiments }\end{array}$ & Apel et al. (2013b) & 2013 & Conference & ICSE \\
\hline $\mathrm{S} 150$ & $\begin{array}{l}\text { Supporting commonality-based analysis } \\
\text { of software product lines }\end{array}$ & Heradio-Gil et al. (2011) & 2011 & Journal & IET Software \\
\hline S151 & $\begin{array}{l}\text { Supporting distributed product configuration } \\
\text { by integrating heterogeneous variability } \\
\text { modeling approaches }\end{array}$ & Galindo et al. (2015) & 2015 & Journal & IST \\
\hline S152 & $\begin{array}{l}\text { Supporting Online Updates of Software } \\
\text { Product Lines: A Controlled Experiment }\end{array}$ & Michalik et al. (2011b) & 2011 & Conference & ESEM \\
\hline S153 & $\begin{array}{l}\text { Supporting program comprehension in large } \\
\text { preprocessor-based software product lines }\end{array}$ & Feigenspan et al. (2012) & 2012 & Journal & IET Software \\
\hline S154 & $\begin{array}{l}\text { Symbolic Model Checking of Product-Line } \\
\text { Requirements Using SAT-Based Methods }\end{array}$ & Ben-David et al. (2015) & 2015 & Conference & ICSE \\
\hline $\mathrm{S} 155$ & $\begin{array}{l}\text { SyMPLES-CVL: A SysML and CVL } \\
\text { Based Approach for Product-Line } \\
\text { Development of Embedded Systems }\end{array}$ & Chiquitto et al. (2015) & 2015 & Conference & SBCARS \\
\hline S156 & $\begin{array}{l}\text { Synthesis of Attributed Feature } \\
\text { Models from Product Descriptions }\end{array}$ & Becan et al. (2015) & 2015 & Conference & SPLC \\
\hline S157 & $\begin{array}{l}\text { Test control algorithms for the validation } \\
\text { of cyber-physical systems product lines }\end{array}$ & Arrieta et al. (2015) & 2015 & Conference & SPLC \\
\hline S158 & $\begin{array}{l}\text { Test order for class-based integration } \\
\text { testing of Java applications }\end{array}$ & Hashim et al. (2005) & 2005 & Conference & QSIC \\
\hline S159 & $\begin{array}{l}\text { Testing and inspecting reusable product } \\
\text { line components: First empirical results }\end{array}$ & Denger and Kolb (2006) & 2006 & Conference & ISESE \\
\hline S160 & $\begin{array}{l}\text { Testing Software Product Lines } \\
\text { Using Incremental Test Generation }\end{array}$ & Uzuncaova et al. (2008) & 2008 & Conference & ISSRE \\
\hline S161 & $\begin{array}{l}\text { The effects of visualization and interaction } \\
\text { techniques on feature model configuration }\end{array}$ & Asadi et al. (2016b) & 2016 & Journal & $\begin{array}{l}\text { Empirical Software } \\
\text { Engineering }\end{array}$ \\
\hline S162 & $\begin{array}{l}\text { TIRT: A Traceability Information Retrieval } \\
\text { Tool for Software Product Lines Projects }\end{array}$ & Santos et al. (2012) & 2012 & Conference & EUROMICRO SEAA \\
\hline S163 & $\begin{array}{l}\text { Toward automated feature model configuration } \\
\text { with optimizing nonfunctional requirements }\end{array}$ & Asadi et al. (2014) & 2014 & Journal & IST \\
\hline S164 & $\begin{array}{l}\text { Toward recovering component-based } \\
\text { software product line architecture } \\
\text { from object-oriented product variants }\end{array}$ & Eyal-Salman and Seriai (2016) & 2016 & Conference & SEKE \\
\hline S165 & $\begin{array}{l}\text { Towards the effectiveness of a variability } \\
\text { management approach at use case level }\end{array}$ & Marcolino et al. (2013b) & 2013 & Conference & SEKE \\
\hline S166 & $\begin{array}{l}\text { Towards Validating Complexity-based Metrics } \\
\text { for Software Product Line Architectures }\end{array}$ & Marcolino et al. (2013a) & 2013 & Conference & SBCARS \\
\hline S167 & $\begin{array}{l}\text { Using a rule-based method for detecting } \\
\text { anomalies in software product line }\end{array}$ & Elfaki et al. (2014) & 2014 & Journal & $\begin{array}{l}\text { Research Journal } \\
\text { of Applied Sciences, } \\
\text { Engineering and } \\
\text { Technology }\end{array}$ \\
\hline S168 & $\begin{array}{l}\text { Using background colors to support program } \\
\text { comprehension in software product lines }\end{array}$ & Feigenspan et al. (2011) & 2011 & Conference & EASE \\
\hline S169 & $\begin{array}{l}\text { Using Feature Diagrams with Context } \\
\text { Variability to Model Multiple Product } \\
\text { Lines for Software Supply Chains }\end{array}$ & Hartmann and Trew (2008) & 2008 & Conference & SPLC \\
\hline S170 & $\begin{array}{l}\text { Variability Identification and Representation } \\
\text { in Software Product Line UML Sequence } \\
\text { Diagrams: Proposal and Empirical Study }\end{array}$ & Marcolino et al. (2014a) & 2014 & Conference & SBES \\
\hline S171 & $\begin{array}{l}\text { Verification of Software Product } \\
\text { Line artefacts: A checklist to } \\
\text { support feature model inspections }\end{array}$ & Mello et al. (2014) & 2014 & Journal & JUCS \\
\hline S172 & $\begin{array}{l}\text { Visualization and exploration of optimal } \\
\text { variants in product line engineering }\end{array}$ & Murashkin et al. (2013b) & 2013 & Conference & SPLC \\
\hline S173 & $\begin{array}{l}\text { Where has all my memory gone? Determining } \\
\text { memory characteristics of product variants } \\
\text { using virtualmachine-level monitoring }\end{array}$ & Lengauer et al. (2014) & 2014 & Conference & VaMoS \\
\hline S174 & $\begin{array}{l}\text { XTraQue: Traceability for product } \\
\text { line systems }\end{array}$ & Jirapanthong and Zisman (2009) & 2009 & $\begin{array}{l}\text { Conference } \\
\text { Modeling }\end{array}$ & Software and Systems \\
\hline
\end{tabular}

